\title{
Use of Mathematical Approaches for Addressing COVID-19 Pandemic - a Critical Review
}

\author{
Rogelio Ochoa-Barragán ${ }^{1}$ · Aurora del Carmen Munguía-López ${ }^{1}$ José María Ponce-Ortega ${ }^{1}$ (C)
}

Received: 14 April 2021 / Revised: 22 June 2021 / Accepted: 11 July 2021 / Published online: 27 July 2021

(c) The Author(s), under exclusive licence to Springer Nature Singapore Pte Ltd. 2021

\begin{abstract}
The COVID-19 pandemic has caused crises in all fields in which the human race develops. This manuscript reviews various strategies and models developed to deal with the effects of the COVID-19 pandemic generated in different areas, such as vaccine logistics, energy consumption, environmental impact, economic impact, and the management of medical resources. Through this review, it can be observed how the proposed strategies can be compatible with each other and can lead to a greater benefit if they are used together. Some of them are designed to obtain short-term benefits (such as vaccine logistics), while the others are considered long-term benefits (such as economic stabilization). The main objective of this work is to show the reader strategies already established to combat the effects produced by the pandemic that can serve as a guide for the development of new and more robust strategies to achieve greater benefits.
\end{abstract}

Keywords COVID-19 $\cdot$ Pandemic $\cdot$ Mathematical models $\cdot$ Process systems engineering

\section{Introduction}

The world has witnessed multiple pandemics throughout its history; we are currently facing the one generated by the COVID-19 which has caused a radical change in the lifestyle of people around the world (Saadat et al. 2020). Despite technological advances in the medical area, it has been impossible to prevent a worldwide spread of the virus, as well as a high degree of mortality, taking us by surprise due to the great lack of foresight in health management (Inkster et al. 2020). What really matters are the decisions to be made from now on, since the current pandemic has generated not only health problems, but also problems of different types such as environmental problems due to a fairly significant increase in sanitary waste, and a large increase in the consumption of plastics (Patrício-Silva et al. 2021).

The economic impact related to the pandemic has been affected mainly by the decrease in industrial production capacity, which also causes problems in the distribution of food and medical supplies (it directly affects the supply

José María Ponce-Ortega

jose.ponce@umich.mx

1 Chemical Engineering Department, Universidad Michoacana de San Nicolás de Hidalgo, Francisco J. Mujica S/N, Ciudad Universitaria, 58060 Morelia, Michoacán, México chain) and by the financial impact on the market and companies (Guan et al. 2020).

From a kinder point of view, we can affirm that the response to the global pandemic has generated extensive advances in various areas. One of the most notable is the impressive improvement in vaccine development. Previously, vaccines took more than 10 years to develop, while the vaccine for COVID 19 was developed in a record time of less than a year (for vaccines such as those developed by Pfizer, Moderna, Gamaleya, and AstraZeneca) (Silveira et al. 2021). Another undeniable great advance is the development of digital technologies, which has played a fundamental role in preserving the economy and education by creating teleworking systems and mobile platforms that make it possible to work from anywhere (Dwivedi et al. 2020). However, these benefits are not observable throughout the world, since in developing countries, there is a high level of deficiencies at a technological level. Here, it has not been possible to observe these benefits for people in unfavorable economic conditions or in rural areas. Therefore, teleworking becomes a luxury that only certain people can reach in developing countries (Kanellopoulos 2011). In addition, there is a psychological discomfort associated with the educational level and the workload that can affect the population depending on their lifestyle and habits (De Sio et al. 2021). 
Other reviews have focused on the critical assessment of COVID-19 prediction models involving epidemiological modeling (Harjule et al. 2021), artificial intelligence applications (Mohamadou et al. 2020), and prediction models (Wang et al. 2020a). However, in this work, we focus on models and strategies addressing other types of issues that arose due to the COVID-19 pandemic. These problems include four main areas: vaccine allocation, energy management, waste management, and medical resource management. Therefore, the main objective of this work is to investigate and review studies including these topics. We focus on works using mathematical approaches and strategy-based analysis to address these problems. We also highlight the differences between these approaches to propose implementations or improvements and carry out feedback that may be useful for future research. This work is organized as follows:

- First, the models and strategies for vaccine logistics are integrated, summarized, and compared.

- Different energy management strategies are presented and compared, where we can observe from saving strategies to changes in the urban organization that allow minimizing energy consumption.

- The papers presented related to waste management are analyzed and a direct relationship with alternative energy sources and a positive generation of economic impact are sought.

- The advantages and disadvantages of the different possible strategies that could be followed to reduce the economic impact generated by the pandemic are analyzed, showing the possibilities of mathematical models based on the food-energy-water-waste nexus.

- The different possibilities between strategies for the management of medical resources are shown, where models based on medical data are compared with strategies with ethical bases.

\section{Models and Strategies}

\section{COVID-19 Vaccine Allocation}

A fundamental aspect when the vaccination campaigns start is the decision of who should be vaccinated first. A vaccination campaign performed without the correct prioritization of certain individuals can cause the infection rate not to decrease as expected, thus causing more deaths and a longer period of isolation at a global level (Craxì et al. 2021). On the other hand, the prioritization of the correct individuals based on previous epidemics shows that depending on the production capacity of the vaccines and their respective efficiency, it can lead to different scenarios where priorities change as a function of these variables as shown by Matrajt et al. (2020) who developed a mathematical model capable of showing a rational prioritization of vaccines based on their efficacy and availability. Currently, the existing vaccines on the market exceed 70\% of effectiveness (unknown information at the time of publication of the study by Matrajt et al. (2020)), which implies that the efficacy variable can be ruled out. However, we are currently facing a low availability of the vaccine in much of the world. This problem arose due to the low production capacities compared to the enormous demands in the world. Furthermore, another important issue is the enormous purchasing power of certain countries which demand most of the produced vaccines. Consequently, countries with limited purchasing power may receive only enough vaccines for an exceedingly small percentage of their population (Torres-Ramírez and Orozco-Rivera 2020).

To establish a correct distinction between groups, Matrajt et al. (2020) decided to perform a population division based on age in order to reduce the total number of symptomatic infections, total deaths, the maximum number of hospitalized patients requiring intensive care units (ICU), and the maximum number of hospitalized patients that do not require ICU. The proposed division is as follows: 0-19 years old, 20-49 years old, 50-64 years old, 65-74 years old, and 75 years old and older. This division makes it possible to reduce the dimensions of the optimization problem. Also, it allows making a clinical distinction between the people involved since people of the age of 0-19 have a lower probability of spreading the virus in the same way as people over 65 years old. People who belong to the group of 20-49 and 50-64 years old are the ones most likely to spread the virus. This occurs because in this age range, the people have the greatest mobility in urban areas (where there is a high population density). Therefore, the recommendations to follow are defined based on the flow diagram of Fig. 1.

The solutions obtained by Matrajt et al. (2020) are based on evidence and appear to be an effective way to reduce the death rate generated by the COVID-19. However, there is a debate whether it is ethically acceptable or not, as it may be politically accepted upon vaccinating young people first over older people. This topic has been widely discussed by Emanuel et al. (2020). Here, the discussion of who should have a higher priority from the ethical point of view is deepened, where a different series of factors intervene that may have a greater or lesser weight depending on the viewer.

Recently, Munguía-López and Ponce-Ortega (2021) developed a strategy for the distribution of vaccines that implements the use of distribution schemes based on the theories of justice of Social Welfare, Rawls, and Nash. With these schemes, it is intended to reach an optimal and fair solution through the evaluation of parameters related to the medical area, such as the sectors of the population affected by autoimmune diseases or the elderly (population with higher epidemiological risk). By ranking the stakeholders 
Fig. 1 Vaccination campaign trend according to the Matrajt model when the available vaccines have effectiveness greater than 70\% (Matrajt et al. 2020)

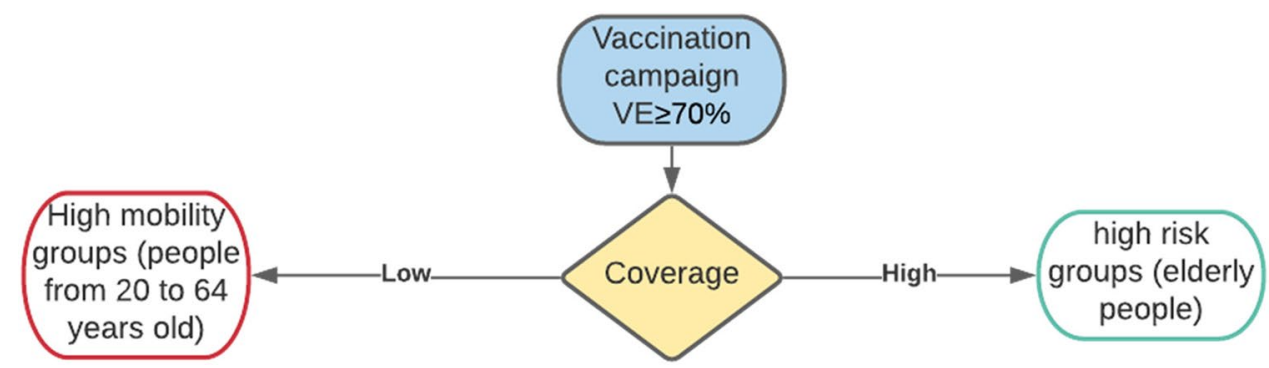

(states of a country in this case) by population density and COVID-19 infection rate, solutions that clearly show how to distribute the available vaccines throughout each state are found. Thus, it is possible to find different allocations of vaccines according to the distribution scheme used. For instance, the Social Welfare scheme favors those states with the largest population without considering the other parameters. The Rawlsian scheme allocates the minimum to each state. Finally, the Nash scheme provides an allocation that does not favor the stakeholders depending on their scales. Each scheme can be useful under different contexts (see Fig. 2). This strategy can be applied to any case study including different scales or regions.

In South Korea, Shim (2021) developed a mathematical model for the optimal allocation of vaccines to minimize the rate of infections, deaths, and years of life lost. Minimizing years of life lost implies generating a model based on ethics. It should be noticed that this type of models can generate some controversy, since by prioritizing years of life lost, people belonging to vulnerable groups (such as people with autoimmune diseases or people of the third age) go to the background, which from a utilitarian perspective (a solution that maximizes the benefits of the majority of the population) could be viable. However, from a moral point of view, it might not be the best option. This type of dilemma is the main reason why mathematical models based on ethics are especially difficult to develop. Nevertheless, this methodology is based on several population factors, such as distribution by ages of the population (like the Matrajt methodology) and contact structures. The model can be used for different levels of effectiveness of the distinct types of vaccines available. The age-structured model of COVID-19 transmission and vaccination is based on the possible routes that individuals can follow during the interaction with their environment. This structure is depicted in Fig. 3.

According to this approach, it is necessary to describe the same route for vaccinated individuals and non-vaccinated individuals since the effectiveness of the available vaccines is different from $100 \%$. Therefore, although to a lesser amount, vaccinated individuals may present symptoms. The model also considers the basic reproductive number, which calculates the approximate number of people who can be indirectly infected by each asymptomatic and symptomatic individual. Thus, the model assumes that unvaccinated

Fig. 2 Strategy for the allocation of vaccines based on the implementation of justice schemes (Munguía-López and Ponce-Ortega 2021)

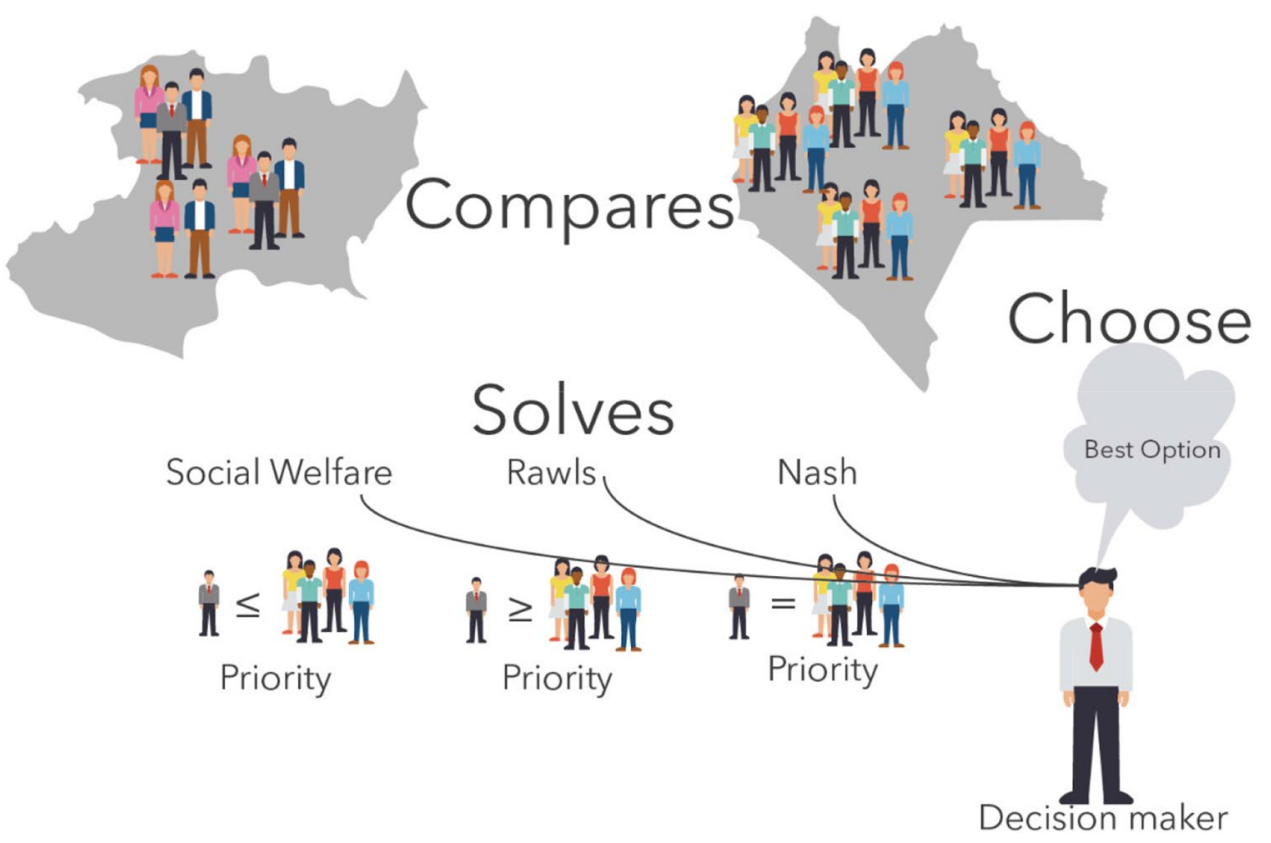


Fig. 3 Contact structure that describes the possible routes to be followed by vaccinated and unvaccinated individuals of different ages

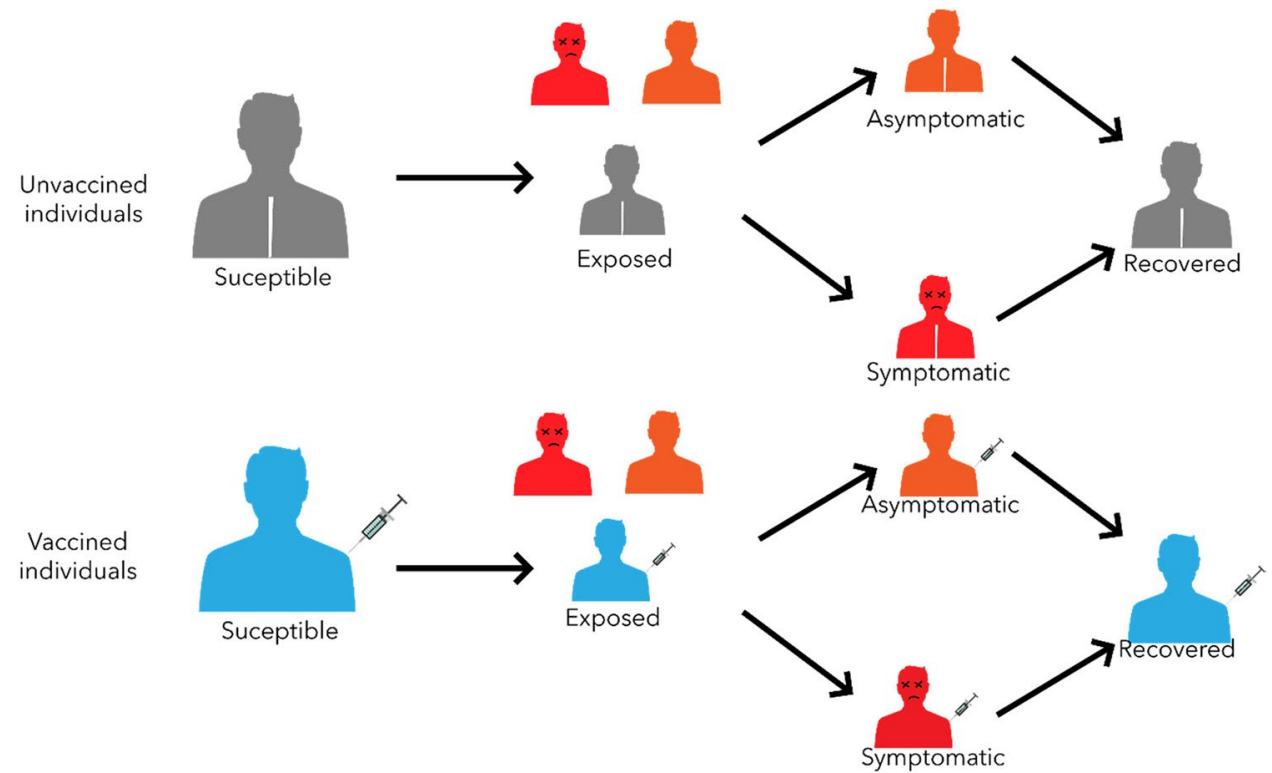

people are initially susceptible, and even vaccinated people can become infected at a reduced rate. The mathematical model can minimize total infections, total deaths, or the total number of years of life lost. To estimate this last measurement, the model multiplies the standard life expectancy of each age group by the deaths caused by the virus. This implies that saving the life of a young individual translates into reducing the total number of years lost. The opposite occurs for an older person, which leads to prioritize the vaccination of young individuals. This approach can be especially useful when the available vaccines are not sufficient to benefit more than half of the population in a given region.

Later, Matrajt et al. (2021) raised the idea of carrying out a single-dose vaccination campaign using vaccines that require two doses (considering that most currently available vaccines require two doses), with the purpose of doubling the number of people benefited by the vaccine. Of course, this action reduces its effectiveness but is a viable alternative to combat the infection. It is not the optimal method, but it is especially useful in regions with low access to vaccines. This is not the first time this has happened; in Zambia, a single-dose campaign of oral inactivated cholera vaccine (which also requires two doses) was used in a recent cholera outbreak. Here, the population was vaccinated with a single dose, and subsequently (months later), a second dose was offered to high-risk people (Ferreras et al. 2018). Therefore, the possibility of using a single dose for the COVID-19 vaccine may be viable, especially in countries with little budget to buy enough doses for their entire population. In this context, it is necessary to specify the priority groups, since it must be borne in mind that the efficiency of the vaccine will be lower than expected so that an optimal distribution will play a decisive role in saving as many lives as possible.
The proposal presented in this work consists of a mixed vaccination campaign, that is, prioritizing older adults to receive full treatment (two doses) with the idea that the rest of the population receive only one dose. In this way, the most vulnerable members of society are protected, and the chain of infections produced by the highly mobile population (young population) is reduced (see Fig. 4). Therefore, it is suggested to study the efficacy and durability of using a single dose. Based on these results, these mixed vaccination campaigns could have enormous potential to control the pandemic even faster than using two doses.

A summary of the proposed methodologies for vaccine allocation is presented in Table 1.

The vaccines authorized by some countries and the social groups that were given priority in the respective country are shown in Table 2. Here, it is observed how different the strategies used by each country are, where some countries such as the USA stand out above the others for the number of vaccines that were authorized by their government and for the breadth of their prioritization to the population, in contrast to Switzerland where only two types of vaccines were authorized and the vaccination strategy is not public.

Global energy management has become a challenge since several years ago (Krog and Sperling 2019). This challenge has worsened since the beginning of the pandemic, so the degree of importance of the implementation of methodologies that allow the design, evaluation, and implementation of global energy strategies has become of great relevance.

Chofreh et al. (2021) proposed a methodology that allows decision-makers to analyze, plan, implement, and evaluate global energy strategies, based on the classification of supplier and consumer energy resources. The strategy can be used with different scopes, depending on the addressed case, 
Fig. 4 Population prioritization for mixed vaccination campaign depending on mobility and risk
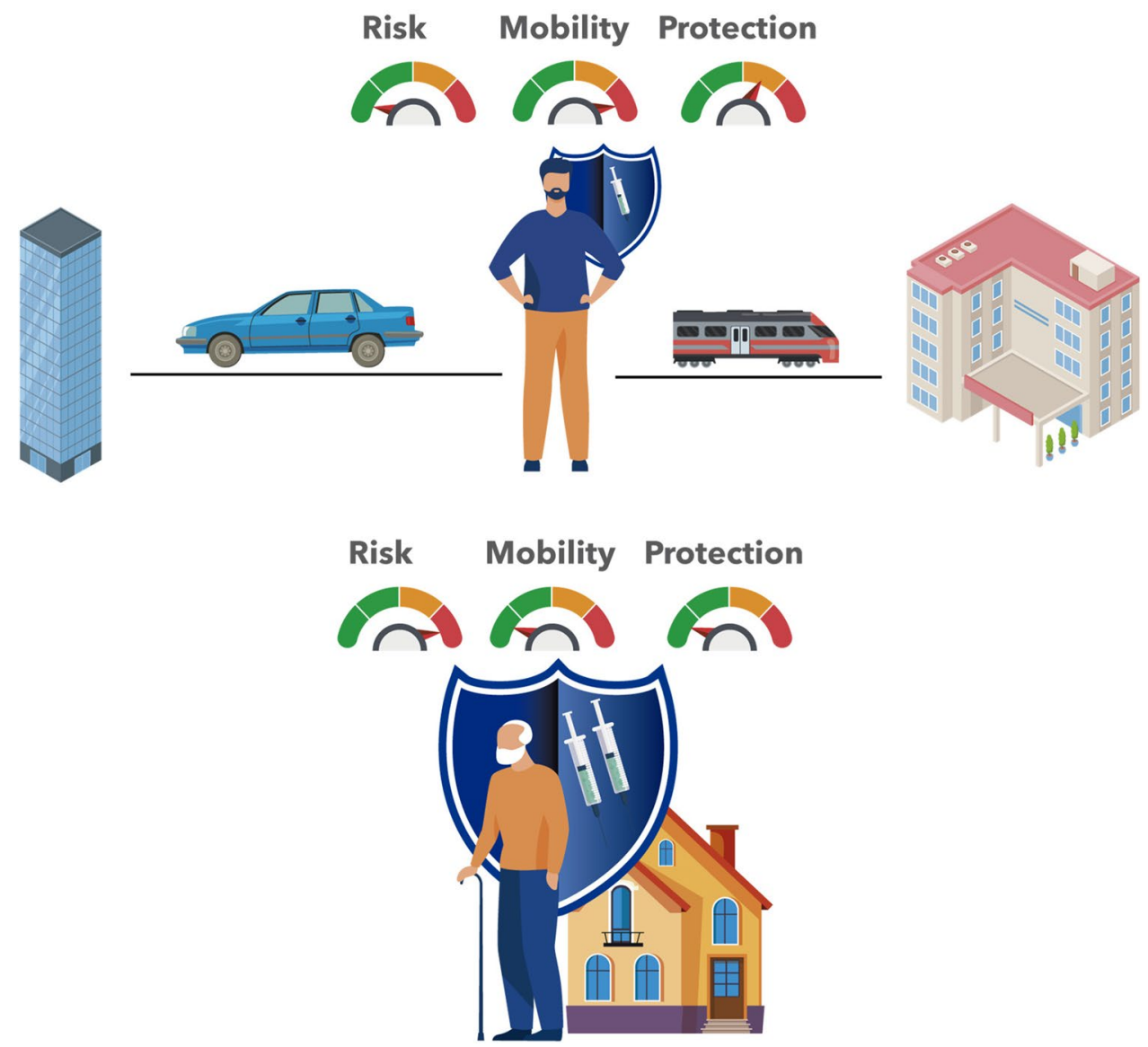

following the sequence of Fig. 5 using an external and internal analysis.

The holistic method proposed is of great help to implement and develop strategies in energy management. The developed strategy on the framework will be especially useful to re-analyze the strategies and actions that require changes to achieve better performance and competitive advantage. This can be particularly useful and offer a good starting point for future research on the topic. Figure 6 shows a more detailed summary of the proposed methodology.

From a general perspective, energy consumption has decreased globally during 2020. However, there was an increase in domestic consumption, but it was not equal to the decrease in industrial energy consumption (Senthilkumar et al. 2020). These increases in domestic consumption are mainly due to the implementation of the home office and telemedicine (Saadat et al. 2020; Perniola et al. 2020). These reductions in energy consumption may be beneficial for the environment; however, social distancing and the fact of living in this new COVID-19 world imply that the main generators of environmental impacts also change. An example of this is the one presented by Jiang et al. (2021). They addressed issues related to energy, dividing their research into four main sections: the emergency situation and its impacts, environmental impacts and stabilization of energy demand, recovery of energy demand, and lessons and emerging opportunities.

Spatial and temporal variations (in energy consumption) turn out to be quite complicated to deal with. Therefore, this study could serve as a guide for future lines of research that aim to increase energy efficiency and promote energy savings. Here, they recommend paying special attention to the generation of medical and municipal waste, as well as to the energy-related atmospheric emissions and water-borne pollution.

Another important factor highlighted in this work is how working from home has significantly reduced energy consumption in most of the world (due to mandatory confinement). Figure 7 shows the reductions in electricity consumption compared to 2019 where consumption had not been affected by the pandemic. However, several studies (Senthilkumar et al. 2020; Zhang et al. 2020; Abu-Rayash and Dincer 2020; Fan et al. 2020) indicate that recreational travel and the large increase in domestic consumption could outweigh the benefits obtained from reduced travel. These trade-offs are represented in Fig. 8.

Alternatives to reduce energy consumption during the pandemic and even after are required due to the great 
problem generated by the current expansion of large cities around the world. For instance, the plan of the neighborhoods of $20 \mathrm{~min}$ ( SGV 2016) and the elaboration of the 15-min city (Sisson 2020) have been proposed. The latter consists of a reorganization-reconstruction of existing cities that can help post-pandemic recovery by allowing its inhabitants to meet most of their needs in an approximate distance of $15 \mathrm{~min}$ (walking or biking) and shifting the use of cars for more specific and non-daily activities (see Fig. 9). Implementing 15-min cities reduces energy consumption and reduces pollution associated with means of transport (Reimer 2020); this restructuring also allows easy access to services and goods which helps preserve the supply chain, which has been widely affected by this pandemic. However, a disadvantage of these cities is the existing limitation in the structure itself, which does not consider enough industries or businesses. This problem makes young people migrate to larger cities or makes them move longer distances, increasing mobility for this sector of the population. Therefore, it could also be necessary to create new industries and businesses that avoid the young population migrating. The inclusion of incentives from the government may be required to do this; however, the potential benefits justify them.

Klemeš et al. (2020) proposed different strategies to reduce energy consumption and environmental impact in different areas. They discussed that although there are different types of face masks, the main characteristic of importance between one and the other may be their effectiveness. However, these indices do not necessarily mean that there is a lower probability of infection since the certification of protective masks normally requires a particle penetration of $300 \mathrm{~nm}$ (a requirement that certified cloth face masks also meet). Therefore, they conclude that reusable face masks could reduce not only the energy consumption associated with their manufacture but also reduce the waste generated by them. In addition to reusable face masks, there is still a wide margin for improvement. For instance, Konda et al. (2020) discussed the implementation of combined effects of electrostatic and physical filtering in cloth face masks, which allows a significant improvement in their efficiency. Although the use of reusable protective equipment requires some energy expenditure and generates contamination associated with the maintenance and disinfection of the equipment, this equipment has a significantly lower environmental impact than the use of single-use protective equipment can have.

Another relevant part of energy consumption is associated with the production and consumption of disinfectants and antiseptics. The purchase of this type of products has had an increase of $2.315 \%$ in 2019 (Xinhua 2020). Consequently, there is an exponential increase of the production of these items to meet this demand, which leads to large increases in energy consumption and pollution generated. For example, 
Table 2 Different allocation strategies adopted by different countries (The Local 2021; European Commission 2021)

\begin{tabular}{|c|c|c|}
\hline Country & Authorized vaccines & Priority groups \\
\hline France & $\begin{array}{l}\text { Pfizer, Moderna, and Johnson \& Johnson which are } \\
\text { authorized for all age groups and AstraZeneca for elder } \\
\text { people }\end{array}$ & $\begin{array}{l}\text { - Older adults } \\
\text { - Health workers }\end{array}$ \\
\hline Sweden & Pfizer, Moderna, and AstraZeneca & $\begin{array}{l}\text { - People who live in care homes for the elderly } \\
\text { - People who have at-home care } \\
\text { - People working in healthcare and care facilities who have close } \\
\text { contact with people in the above risk groups }\end{array}$ \\
\hline Switzerland & Pfizer and Moderna & $\begin{array}{l}\text { Unlike in some other countries, information as to which vaccines are } \\
\text { given out at which vaccination centers is not made public - mean- } \\
\text { ing you cannot choose a particular center based on the available } \\
\text { vaccines }\end{array}$ \\
\hline Spain & Pfizer and Moderna & $\begin{array}{l}\text { - Elder people } \\
\text { - Patients with chronic conditions }\end{array}$ \\
\hline USA & Moderna, Pfizer, AstraZeneca, and Johnson \& Johnson & $\begin{array}{l}\text { - Healthcare workers } \\
\text { - Persons over } 60 \text { years of age } \\
\text { - Persons whose state of health makes them particularly at risk } \\
\text { - Essential workers outside the health sector } \\
\text { - Workers who cannot socially distance } \\
\text { - Vulnerable socioeconomic groups and other groups at higher risk }\end{array}$ \\
\hline
\end{tabular}

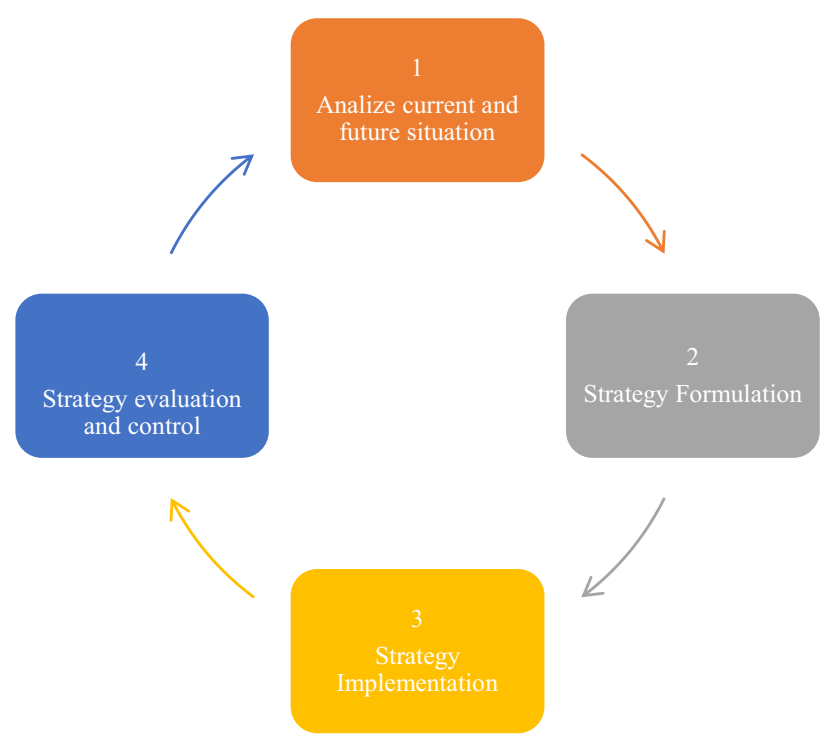

Fig. 5 The main strategy for the framework for energy management ( adapted from Chofreh et al. 2021)

ethanol production increased $20 \%$ in China (FIRI 2021) which means an extra production of $13,549 \times 10^{6} \mathrm{~L}$ in that year, which translates to approximately $181.1 \mathrm{PJ}$ or $181.1 \times 10^{15} \mathrm{~J}$. In this regard, steam disinfection (energybased disinfection process) may require less energy when used as a supplementary disinfection method as presented by Klemeš et al. (2020). The use of these technologies does not plan to replace the use of disinfectants and antiseptics since it is not possible to use steam for all these tasks. Although both options can be used, it is recommended to use steam in those disinfection tasks that are possible due to the low cost of steam disinfection (see Fig. 10), and use ethanol for those disinfection tasks for which steam is not an option. Nevertheless, the joint use of reusable protective equipment with an appropriate selection of the use of disinfection technologies by steam for certain fields can generate a significant decrease in costs, generation of pollutants, and energy consumption considering that $2.63 \mathrm{MJ}$ of energy is needed to transform $1 \mathrm{~kg}$ of water into steam at normal pressure conditions (1 atm).

According to studies by the International Energy Agency (2019), it has been detected that refrigeration systems have tripled energy consumption in buildings in the last two decades. For this reason, Dulce-Chamorro and Martinez-dePison (2021) developed a methodology to improve energy efficiency and performance by forecasting the thermal energy demand of cooling water systems. The prediction of required cooling energy allows to maximize the thermal energy demanded the next day, avoiding an unnecessary accumulation of thermal energy. In order to carry this out, a combined predictive model of artificial neural network (ANN) and support vector regression (SVR) models was developed.

This model is trained with real data from the hospital where it is planned to be used, generating personalized results for each building (see Fig. 11). This methodology was applied in San Pedro Hospital obtaining energy savings of approximately $8 \%$ per year, which represents about 40,000 euros per year. The energy consumption of hospitals has been increased by $20 \%$ (Morawska et al. 2020) which allows the benefits obtained by using this methodology to 


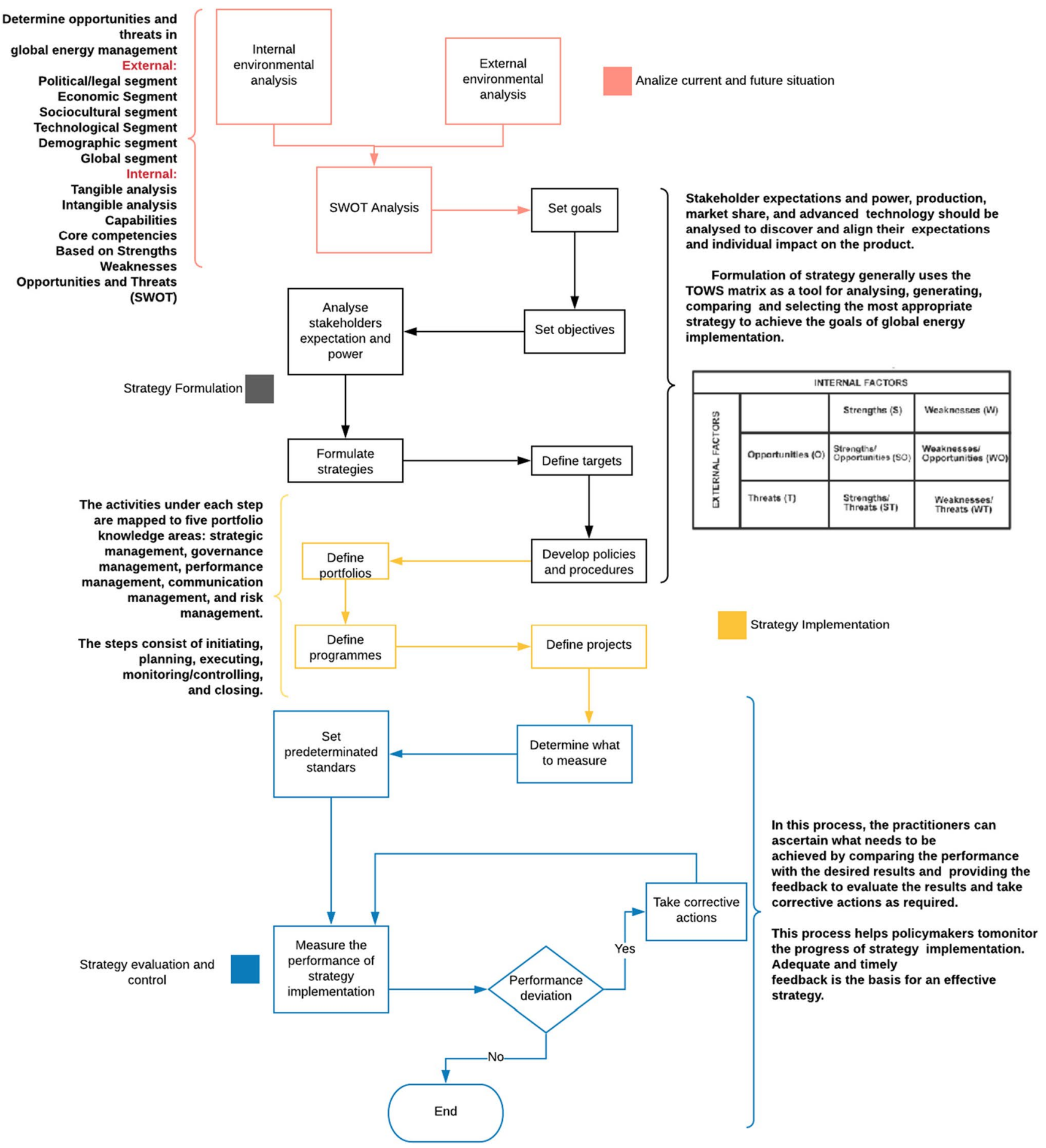

Fig. 6 Summary of the strategy proposed by Chofreh et al. (2021)

be even greater during situations such as the one generated by the COVID-19 pandemic in 2020 .

A summary of the proposed methodologies for the energy management challenges is presented in Table 3.

The world has witnessed positive environmental changes thanks to the pandemic, changes such as cleaner skies and rivers (Gardiner 2020). Unfortunately, these benefits are not equal to the growing generation of solid waste which has increased significantly (Sharma et al. 2020) leading to the implementation of new laws and measurements to reduce the pollution generated (Mallapur 2020). Many types of hazardous wastes including virus-infected masks, gloves, and other 
Fig. 7 Average reduction of monthly weather adjusted electricity demand comparing 2020 to 2019 for March, April, and May 2020 in selected countries

\section{Percent reduction of monthly electricity consumption 2019-2020}

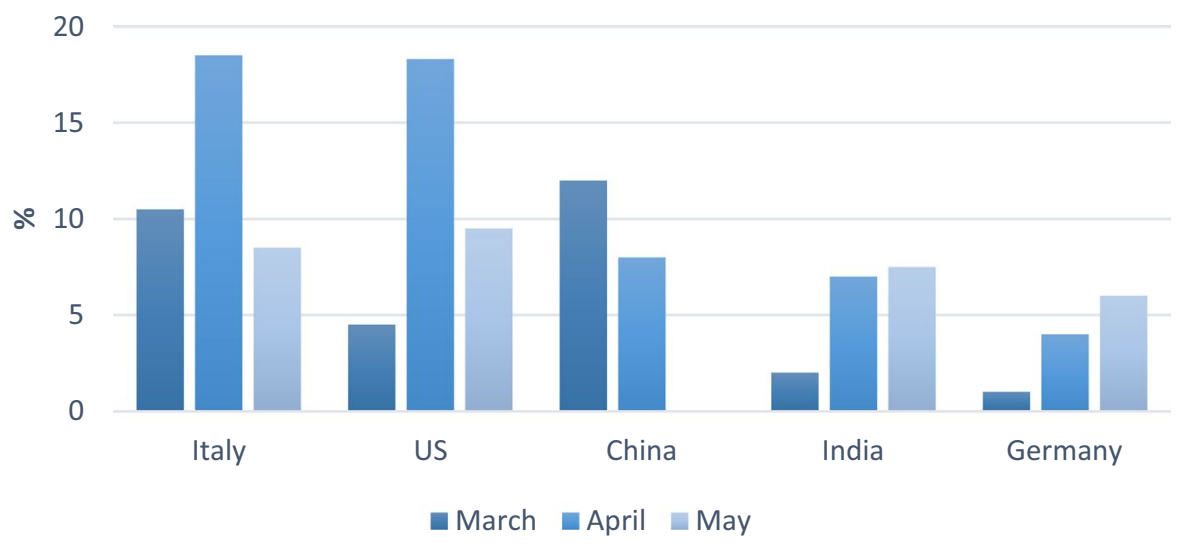

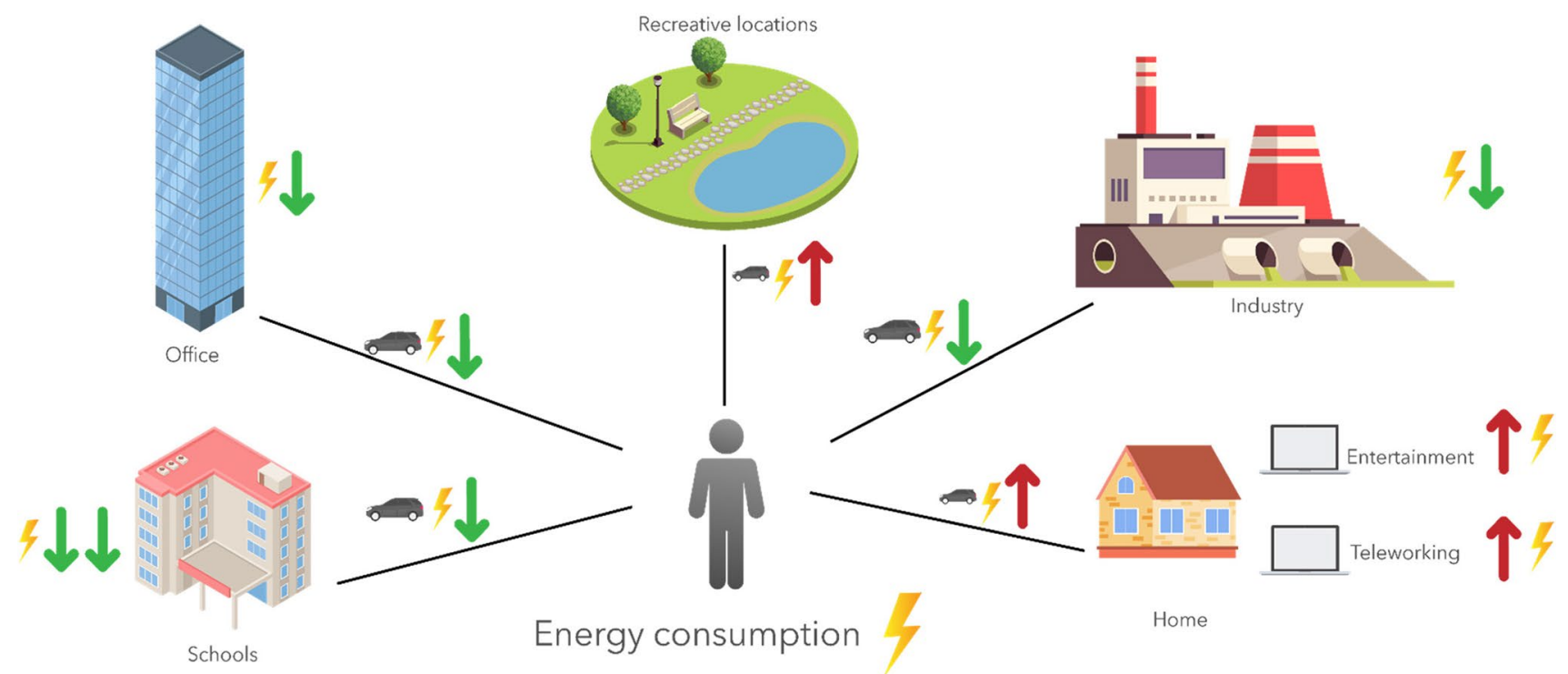

Fig. 8 Comparison of increases and decreases in energy consumption in daily human activities

protective equipment, along with a larger volume of items not necessarily infected, have been disposed of during this pandemic (UNEP 2020).

Ilyas et al. (2020) developed a strategy that consists of using different types of treatment based on costs, the volume of waste generated, the type of bio-medical waste, and the maintenance (see Fig. 12). Depending on these variables, the following treatments can be applied:

- Treatment by incineration: This alternative consists of incinerating the waste in a high-temperature combustion range between 800 and $1200{ }^{\circ} \mathrm{C}$, which is able to kill the pathogen and burning $90 \%$ of the organic matter present. As expected, this type of treatment requires a large amount of energy and produces a large number of emissions of air pollutants.

- Chemical treatment: This type of treatment is based on disinfection treatments that are widely used as a pretreatment in COVID-19 residues and followed by mechanical crushing. The application of this technique presents acceptable performances, a rapid action, and a wide spectrum of sterilization that can kill the pathogen and the microorganisms present as well as deactivate bacterial spores (Wang et al. 2020b).

- Alternative treatments: the alternative treatments presented in this work are mainly two, those that are based 


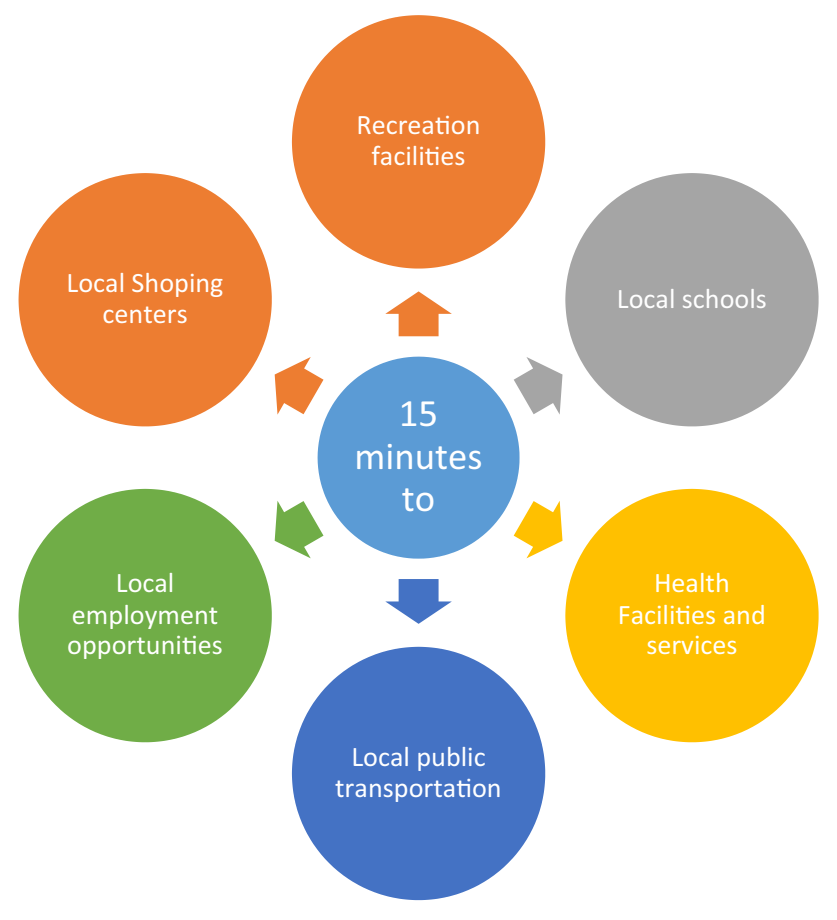

Fig. 9 Main characteristics of the 15-min cities (Sisson 2020)

on pyrolysis techniques at high temperatures and those that are based on the use of microwaves in medium temperature ranges.

By considering the different technologies for waste treatment, it is feasible to develop an optimization model that uses all these strategies based on the desired variables. This model can provide a solution for a significant reduction in energy consumption, costs associated with waste treatment, and environmental impact. In this regard, Zhao and You (2021) analyzed and developed a mathematical optimization model for the food-energy-water-waste nexus, which could help with the environmental and health problems generated by the growing food waste generation during COVID-19. In this work, a multi-period and multi-objective model that estimates and minimizes costs is proposed. Furthermore, it is considered that the food waste can be processed to obtain biogas using an anaerobic digester, converting food waste into a viable alternative in regions where there are large cities. Normally, previous works have proposed a similar approach but only with agricultural waste to produce biogas. Therefore, the proposed variation can be an attractive alternative for large cities without agricultural activity. The foodenergy-water-waste nexus proposed by Zhao and You (2021) is represented in Fig. 13.

In this approach, different scenarios are presented by changing the level of wasted food processed, showing how it affects the trade-offs between the total costs of the process and the unitary costs of processing food waste through an anaerobic digester. Using this strategy, the main income can be seen reflected in the production of electricity and heat. However, it is observed that processing about $2.4 \%$ of the waste generated (in the state of New York in this case), by using a small capacity anaerobic digester, causes unit costs to be greatly reduced. Nevertheless, the entire process is too expensive (total cost), which results in a small profit. Also, they reported that the results have the same trend even raising the percentage of wasted food processed to $37.6 \%$ because this means also increasing the production capacity to $100 \%$. The optimal solution (the one that generates the highest percentage of profit) is based on processing only $23.6 \%$ of food waste and operating the anaerobic digesters at $60 \%$ of their capacity. This
Fig. 10 Cost comparison between chemical and steam methods (SaniVap 2013; Klemeš et al. 2020)

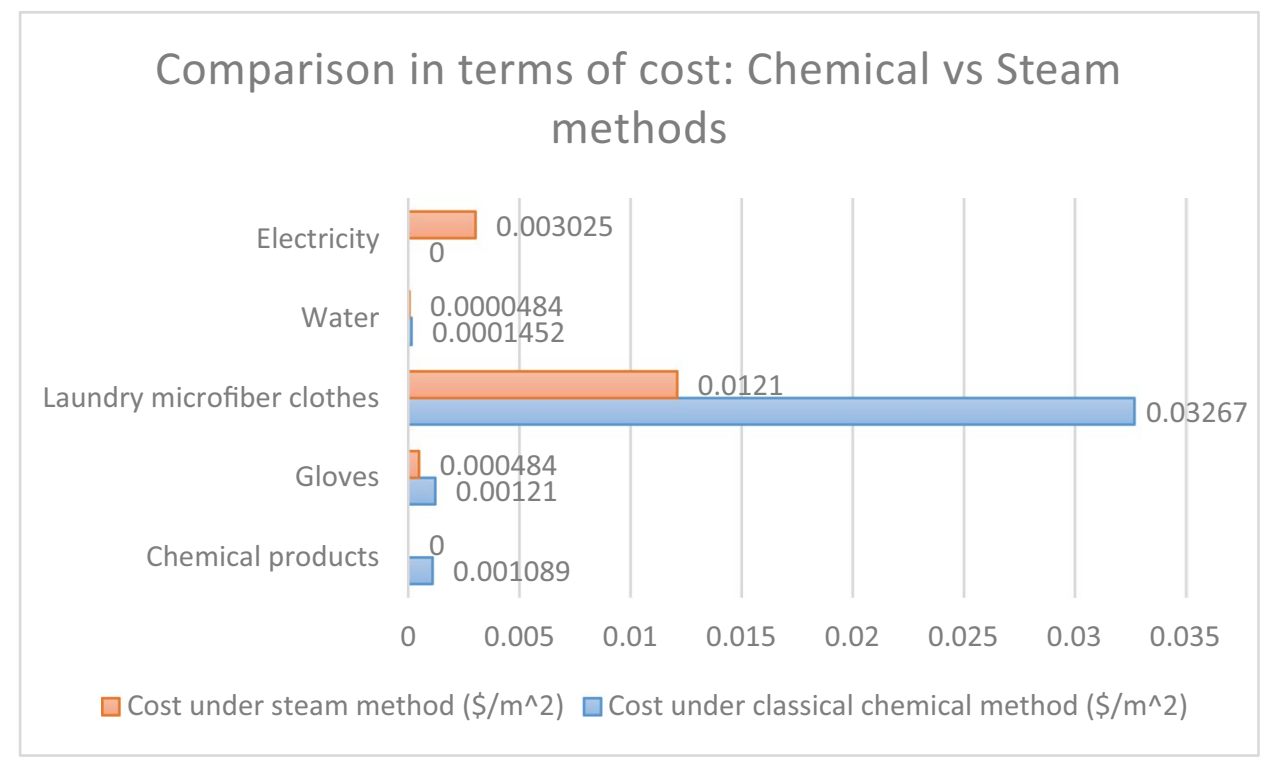


Fig. 11 Solution scheme for hospital refrigeration systems (Dulce-Chamorro and Martinezde-Pison 2021)

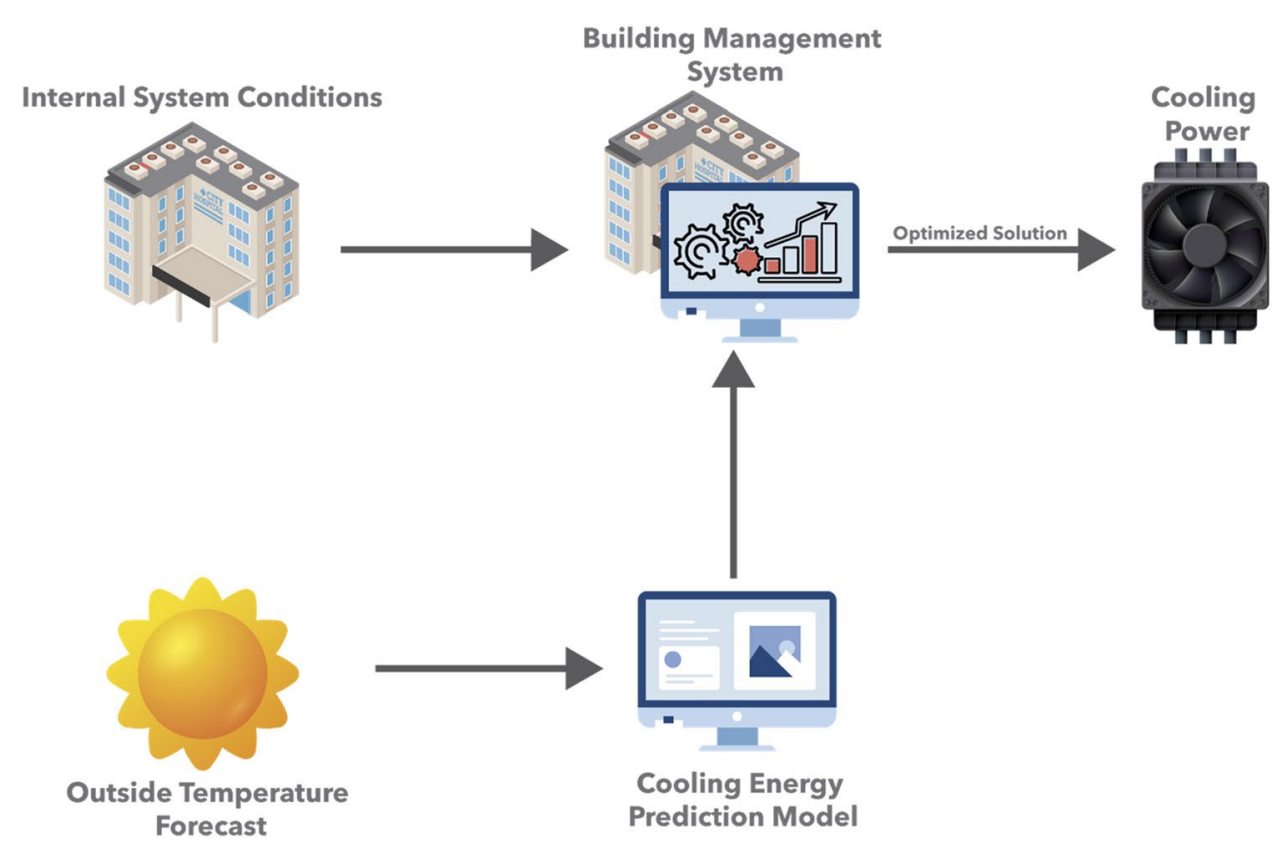

strategy generates excellent results by taking food waste as an energy source, which makes it a great alternative, as long as there is an adequate waste management infrastructure in the region where it is implemented.

Valizadeh and Mozafari (2021) proposed a mathematical model capable of operating under uncertain conditions such as the volume of infectious waste generated in a region, using an objective function that minimizes total costs. This strategy is based on a coalition between contractors that reduce losses of financial costs for poor waste management; this, in turn, encourages contractors to carry out larger coalitions that further reduce total costs. To carry out this strategy, four methods based on game theory (see Fig. 14) were implemented as follows:

1. Shapley Value: It is structured with the objective that the stakeholders form alliances that allow obtaining collective benefits by distributing the profits equitably based on the individual participation of each of the stakeholders (Vesga et al. 2015).

2. The value $\tau$ : It is based on the different contributions of the stakeholders, where if one of these stakeholders wants to increase its benefits, it competes with the other stakeholders to reduce the profits generated from the competition and increase its own profits (Tijs 2003).

3. Core-Center Value: This scheme makes assignments through a "nucleus" (location of the highest concentration of data) generating greater activity among the stakeholders that are closer to this nucleus, which also implies greater benefits (for example, stakeholders that handle a greater volume of waste will cooperate with those that also handle large amounts of waste, obtaining a large part of the profits for themselves) (Faigle et al. 2016).

4. Least core value: Contrary to the previous scheme, here, assignments prioritize stakeholders that are outside the greatest concentration of data, promoting cooperation ensuring the existence of an efficient and stable cost allocation (Schulz and Uhan 2013).

A summary of the proposed strategies to address the COVID-19 waste management challenges is presented in Table 4.

It is a fact that the economy has been strongly affected by the current COVID-19 pandemic. The financial and economic consequences could be observed in the short and medium, and possibly long term throughout the world. These consequences can be estimated in terms of the variations of the gross domestic product (GDP). In this regard, Fig. 15 shows the comparison between the number of total infected people and the variation of the GDP for different countries. Here, we can observe some important differences among countries. For instance, South Korea had an almost insignificant number of COVID-19-infected patients and managed to protect its economy in very efficient way. On the other hand, the USA had a huge number of infected people. However, the used strategy was quite good since its variations in GDP were not so high. Regarding Latin American countries, such as Argentina and Mexico, their GDP decreased considerably. The existing global economic interconnection requires the generation of strategies at an international level that allows 


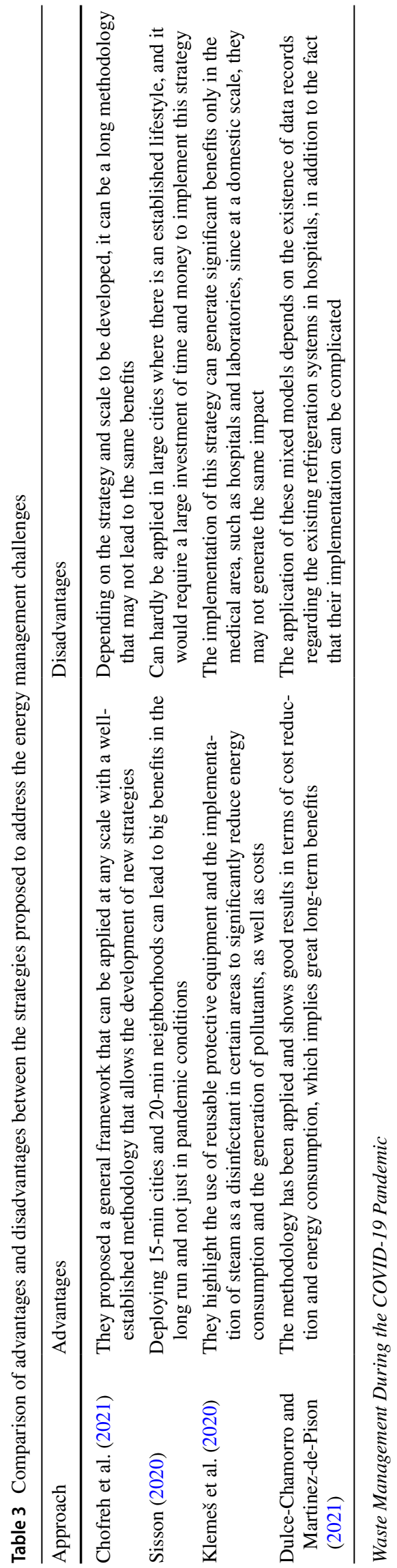

containing viruses and mitigating the possible risks that may be generated in a future pandemic. Thus, an international collective action and investment in the development of technologies that allow adequate containment and protection of the global economy are clearly justified (Song and Zhou 2020).

Wuyts et al. (2020) proposed, as a possible solution to the current economic situation, the development of circular economy models. These models operate under schemes that involve the reuse of waste including certain types of waste that can be used as raw materials for other processes (as long as the nature of the process allows it). An example is the elaboration of alcohol destined for the disinfection of medical areas that can be produced from the waste produced by the breweries. This change would save resources and significantly reduce the environmental impact. Under the proposed strategy, the manufacture of face masks is also implemented from waste from the textile industry, allowing the generation of extra income to these industries and reducing costs to customers. The main challenge of this strategy is based on proposing and managing to close these economic cycles. Therefore, creativity and investment in the development of these cycles are vital, and proper planning could bring great long-term benefits, especially if invested in the development of strategies for the medical-circular economy nexus. A summary of this nexus is depicted in Fig. 16.

Aizenman and Ito (2020) presented two strategies to solve the post-COVID-19 debt. They analyzed their implications for emerging markets and global economic stability. The first strategy consists of returning to the economic model of 2019 before COVID-19. The short-term benefits of this strategy include faster economic growth as long as the difference between the interest rate on public debt and the growth rate is negative, which may seem unlikely. This strategy may involve an increased risk that could trigger a deeper crisis caused by inadequate financial management for a post-pandemic situation, inducing a sudden and prolonged crisis. This strategy was illustrated by evaluating the crisis in emerging markets during the 1980s, triggered by the snowball effect in the USA during 1974-1984. The second strategy involves a two-pronged approach. It involves shifting fiscal priorities from fighting the medical and economic challenges of COVID-19 toward investing in social, medical, and physical infrastructure. Also, it includes promoting a gradual fiscal adjustment with the aim of achieving primary surpluses and debt resilience over time. This strategy is inspired by the one employed by the US government after World War II and its repercussions in the "Phoenix Emergency" of Western Europe and Japan from the destruction of World War II. These strategies are represented in Fig. 17.

With these strategies, quite different results are obtained, since applying the first one can generate apparent benefits in the short term; however, there is a risk for a snowball effect 


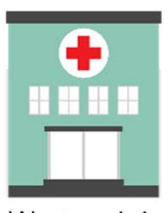

Waste origin

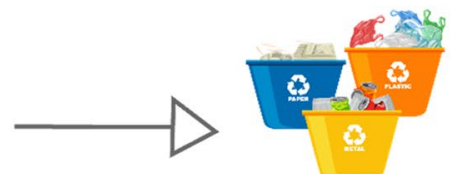

Waste classification

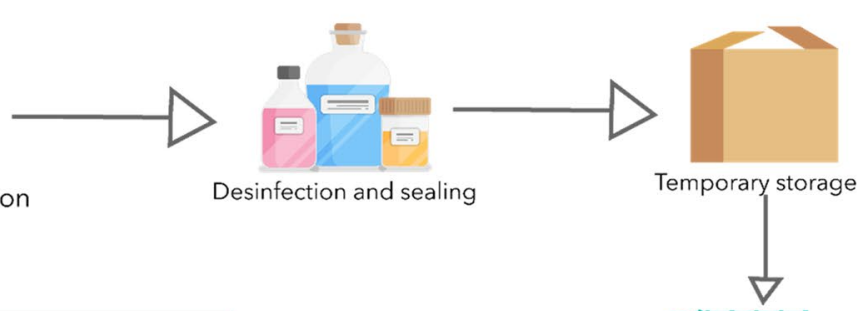

Evaluate Influencial factors
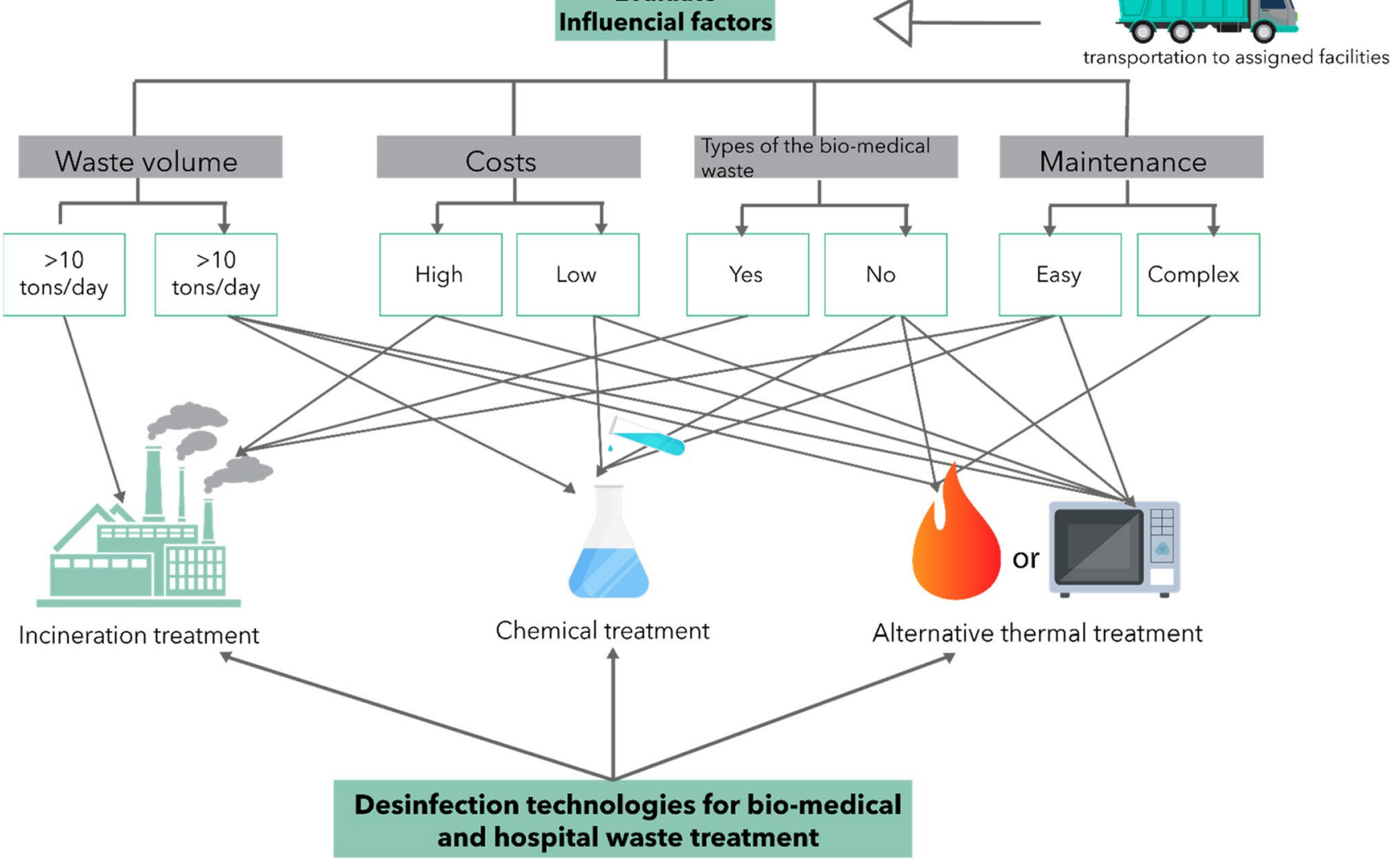

Fig. 12 Solid waste distribution scheme based on the strategy proposed by Ilyas et al. (2020)

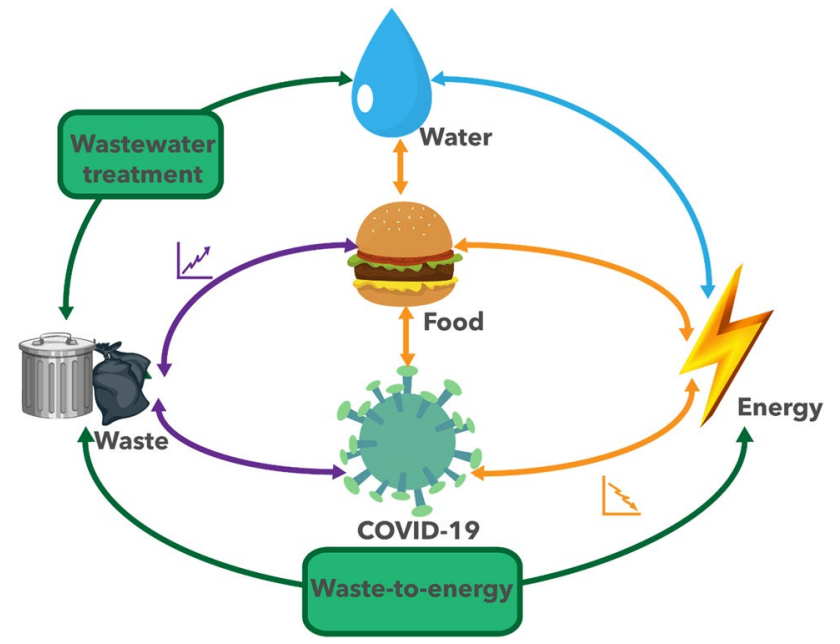

Fig. 13 COVID-19 impact diagram with the food-energy-water-waste nexus ( adapted from Zhao and You 2021) that ends up unleashing a crisis even larger and longer. Thus, in contrast to the second strategy, the benefits may not be visible in the short term but appear to be a safer bet in the long term. Following a post-WWII-like strategy can help stabilize emerging markets and promote global growth. A summary of the proposed strategies to address the COVID19 economic challenges is presented in Table 5.

Under emergency scenarios such as the one generated by the COVID-19 epidemic, proper management of existing resources is needed to preserve a sustainable lifestyle.

During the COVID-19 outbreak in China, hospitals were designated for severely and critically ill COVID-19 patients; the mortality of severely ill patients was $10.4 \%$ and that of critically ill patients was $39.6 \%$ (Wu et al. 2020; Chen et al. 2020; HCHP 2020). These high mortality rates are mainly linked to the oversaturation of hospitals and the scarcity of medical resources, a situation that has been replicated in 
Fig. 14 Strategy based on game theory for infectious waste management

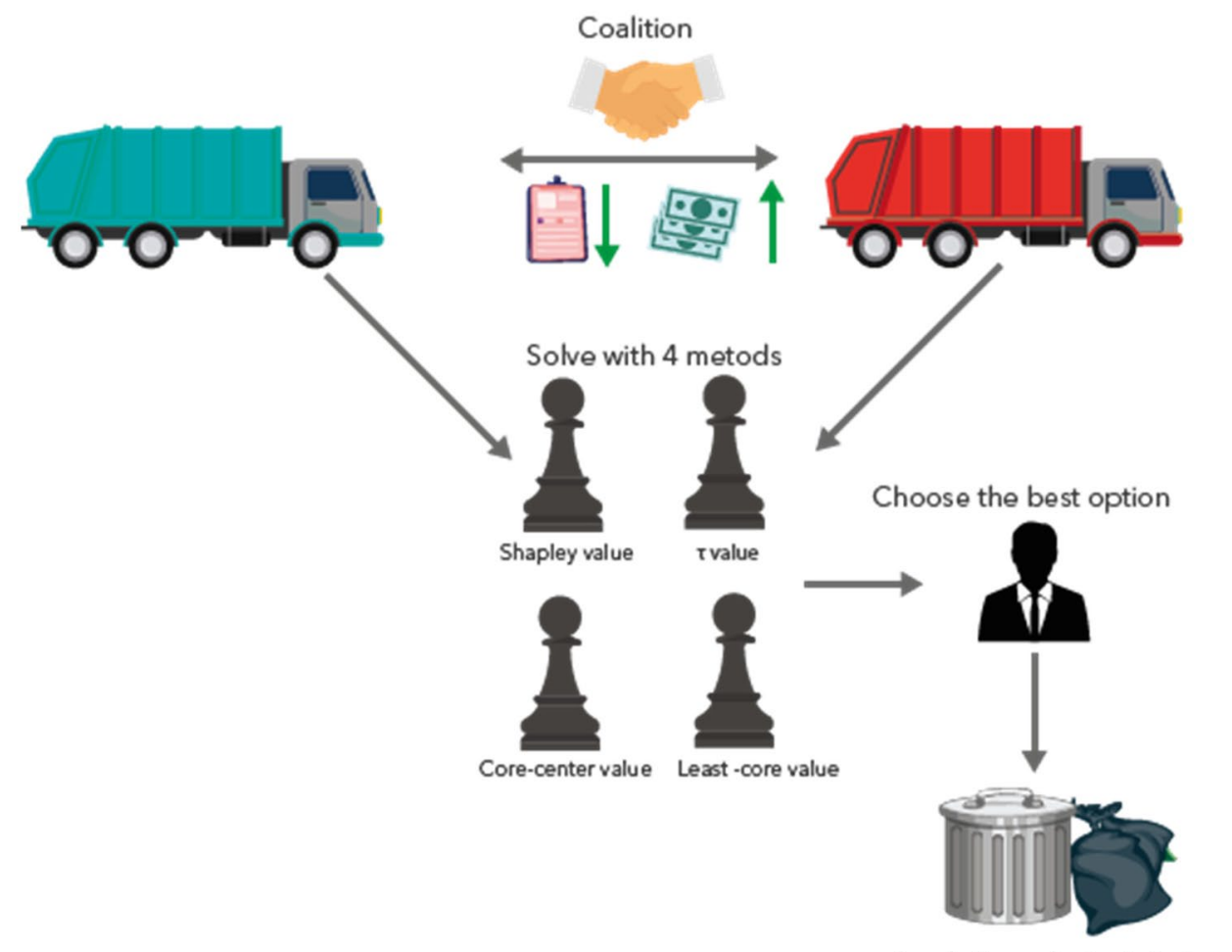

Apply the selected strategy
Mexico and in many other regions (Olivas-Martínez et al. 2021). The lack of medical facilities such as hospitals and laboratories was present even before COVID-19. During the 2018 flu season, there was a lack of medical facilities in the USA (CIDRAP 2021). However, the corresponding measures were not taken to face an equal or greater epidemic. Therefore, the current pandemic highlights the need of funding new hospitals and laboratories in order to face future pandemics by learning from the mistakes of the past.

Hernández-Pérez and Ponce-Ortega (2021) developed a multi-objective optimization strategy based on mathematical programming for emergency scenarios (such as the current pandemic) using meta-heuristic optimization as well as evolutionary optimization algorithms and stochastic optimization. This strategy is based on the uncertainty generated by the use of random factors (it should be noticed that this technique allows finding new sets of solutions for the proposed system).

In this work, the use of both optimization techniques was implemented. To make this possible, a link was established between the algorithms of each approach, developing a code that allows linking Microsoft TM (MS) Excel and GAMS using GAMS data Exchange (GDX) files. The link between these programs is made through the action of a code or subroutine developed in the Visual Basic environment. Using a different series of algorithms, this multi-objective strategy (a social objective and an economic one) can distribute patients in those hospitals saturated to those hospitals with vacancy, either by using their own available medical equipment or by acquiring new equipment. In this way, the number of patients rejected in hospitals due to lack of equipment is minimized, which indirectly contributes to the number of lives saved. Regarding the economic part, it seeks to reduce the costs associated with transportation and the acquisition of new medical equipment (see Fig. 18).

To demonstrate the usefulness of this strategy, two of the states with the most over-demand of patients (New York and New Jersey) and three states with the capacity to serve these patients (Connecticut, Pennsylvania, and Delaware) were taken as a case study getting promising results.

Similarly, Zhu et al. (2021) carried out a statistical analysis that sought to relate blood oxygen saturation ( $\mathrm{SpO} 2)$ with the fraction of inspired oxygen ( $\mathrm{FiO} 2)$ and arterial oxygen pressure $(\mathrm{PaO} 2)$ with $\mathrm{FiO} 2$, taking data from patients who require ventilatory support and those who they do not require it, for the purpose of early detection of those patients who may require intensive care units.

It was found that the $\mathrm{SpO} 2 / \mathrm{FiO} 2$ values that were taken half an hour before intubation compared to the patients who did not require ventilatory support from the onset of the disease to admission differed between the low $\mathrm{SpO} 2 /$ $\mathrm{FiO} 2$ and $\mathrm{SpO} 2 / \mathrm{FiO} 2$ groups. High mortality in patients with low $\mathrm{SpO} 2 / \mathrm{FiO} 2$ during intubation was higher than in patients with high $\mathrm{SpO} 2 / \mathrm{FiO} 2$. Furthermore, the mean arterial pressure of patients with low $\mathrm{SpO} 2 / \mathrm{FiO} 2$ was significantly lower than that of patients with high $\mathrm{SpO} 2 / \mathrm{FiO} 2$. 


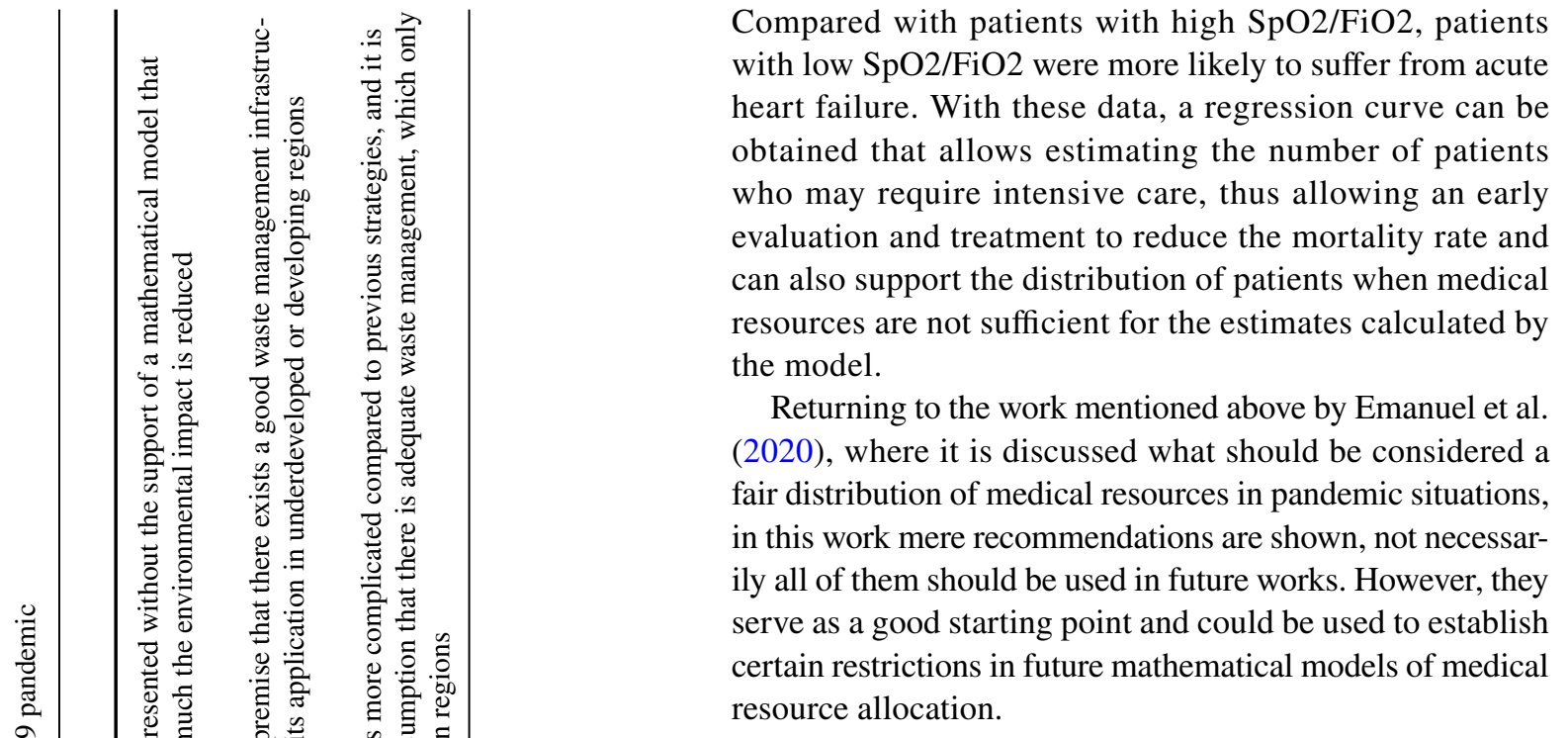

Recommendation 1: In emergency conditions such as the pandemic generated by COVID-19, maximizing the benefits is the most important point. These benefits depend on the viewer, since under different contexts, it may seem a priority to save more lives or save more years of life (Christian et al. 2014), regardless of the priority, the strategy must be applied consistently.

Recommendation 2: The essential personnel (medical personnel) to combat COVID-19 should be prioritized regardless of the approach used, not because their lives have a greater value than the rest of the population, but because in the event that doctors are disabled, all patients, not only those with COVID-19, will be affected, which translates into higher mortality and years of life lost.

Recommendation 3: When there are individuals who are under equal conditions (similar medical prognoses and similar socioeconomic situations), it is sought to use random assignment strategies in such a way that a priority is not established on any of these individuals.

Recommendation 4: The prioritization of individuals should not always be the same in all regions or at all times; it should vary according to the scientific evidence that is presented. For example, younger patients (who spread the disease) should not always be prioritized over elderly patients (who are the patients most affected by COVID-19) (Wu and McGoogan 2020). These priorities depend on the nature of the medical resource to be assigned and its availability.

Recommendation 5: Individuals who participate in research and development of technologies to combat COVID-19 (such as the population that decides to participate in efficacy and safety tests of vaccines) should be given a certain priority for the allocation of medical resources as a reward, thus promoting the contribution of the population to combat the pandemic. 
Fig. 15 Comparison between the accumulated number of infected people and the variation of the GDP during 2020 for different selected countries (ONS 2021)
Fig. 16 Incorporation of new economic cycles to the medicalcircular economy nexus

\section{Variation of GDP in selected countries during 2020}

(\%)
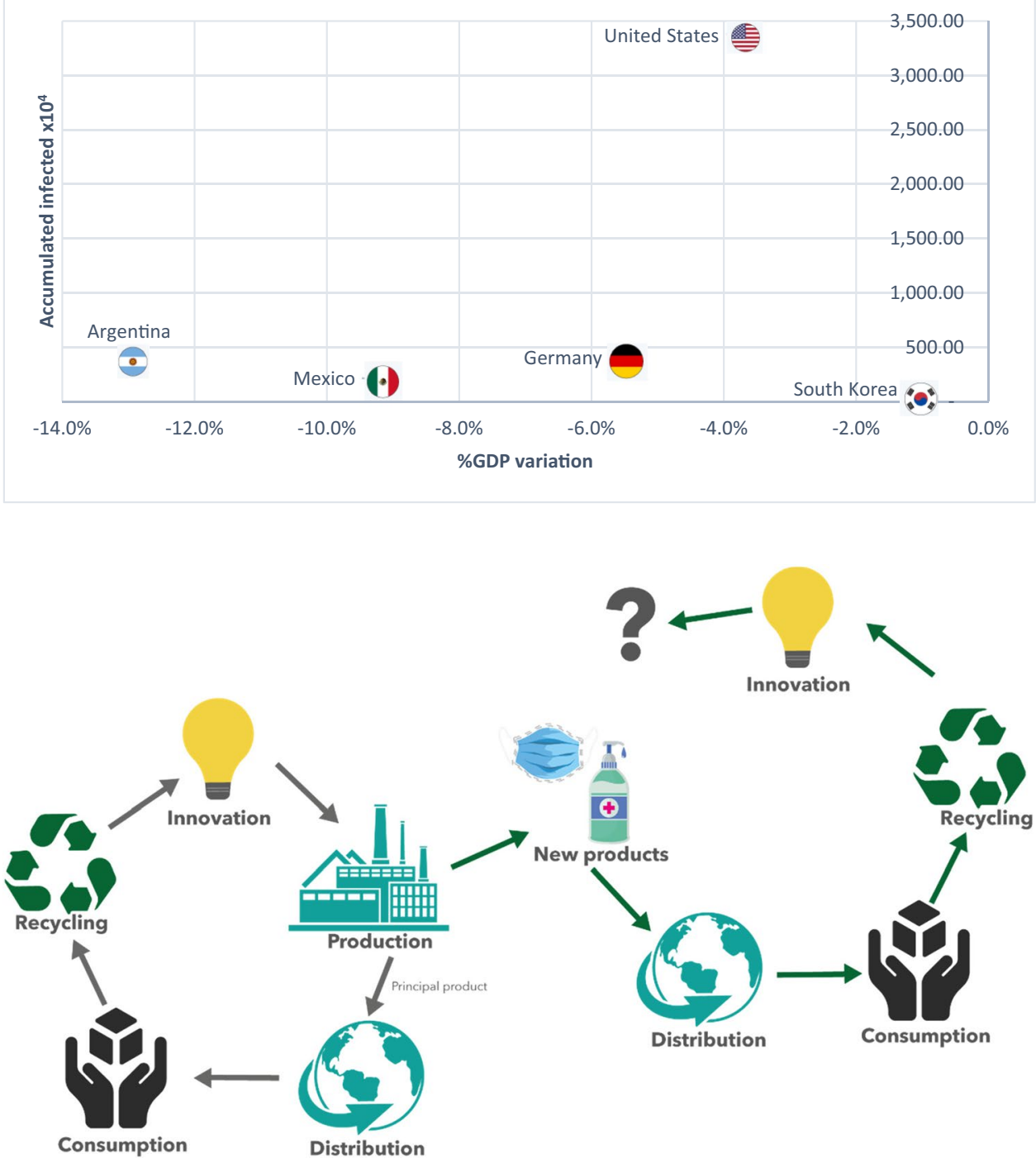

Recommendation 6: Patients should not be prioritized for their medical condition over the role they play in the fight against COVID-19; for example, if a doctor who is on an equal footing with an individual who does not belong to the front line combat against COVID-19 (It is not a doctor) and both require respiratory assistance, under a scenario of scarce resources, it is recommended to give priority to the doctor, since in this way the number of lives and years of life saved is maximized.

Generating a model that considers ethics in decisionmaking is especially complex due to the very nature of the concept, since often, depending on the perspective, ethics can acquire a dialogic nature where ambiguity and contradiction often have to be faced.
In Table 6, a comparison between the different strategies proposed for the distribution of resources can be found.

\section{Future Work}

Different strategies, models, and approaches have been developed as a result of the pandemic caused by COVID-19; this allows future lines of research to be directed to develop deeper analyses that generate novel proposals and greater benefits. In this work, several proposals were reviewed; for some cases, the proposals could be used simultaneously, generating more robust and complex proposals. The following ideas could serve as a starting point for future work: 


\section{Pre COVID-19}

\section{Economic Model}
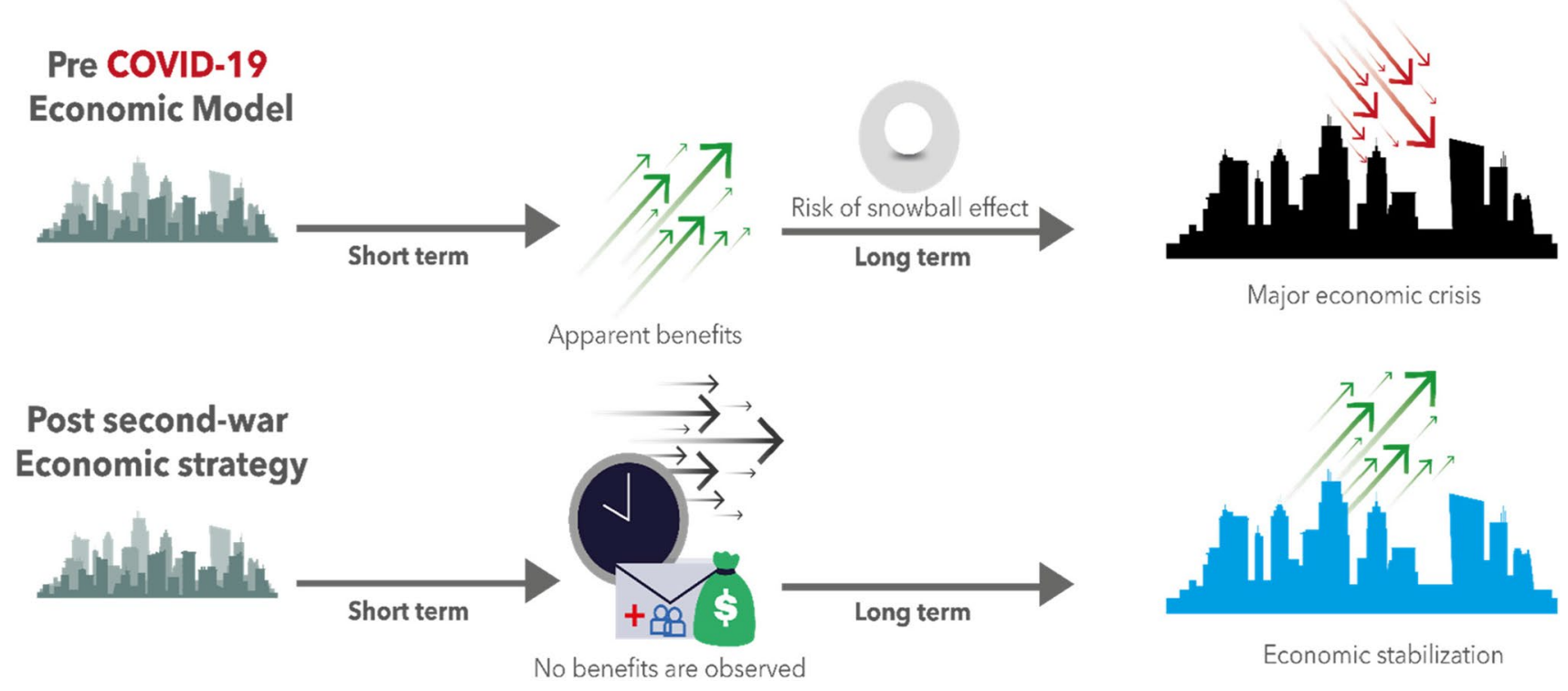

Economic stabilization

Fig. 17 Comparison between possible strategies to use, in the short- and long term

Table 5 Comparison of advantages and disadvantages between the proposed strategies for economy management after the COVID-19 pandemic

\begin{tabular}{llc}
\hline Strategies & Advantages & Disadvantages \\
\hline Wuyts et al. (2020) & $\begin{array}{c}\text { It is a general methodology that serves as a starting point } \\
\text { for new strategies capable of generating a great positive } \\
\text { economic impact and reducing environmental impact } \\
\text { by promoting the circular economy }\end{array}$ & $\begin{array}{c}\text { It requires a considerable investment of time and money } \\
\text { to develop functional economic cycles, and all that this } \\
\text { can generate (mathematical models for example) }\end{array}$ \\
$\begin{array}{l}\text { Aizenman and Ito (2020) } \\
\text { (Pre-COVID-19) }\end{array}$ & $\begin{array}{l}\text { It generates a positive economic impact in the short term. } \\
\text { Simple to implement }\end{array}$ & $\begin{array}{c}\text { There is a likelihood of a snowball effect that could trig- } \\
\text { ger an even bigger economic crisis }\end{array}$ \\
(Post second war strategy) & $\begin{array}{c}\text { There are antecedents that support its possibility of } \\
\text { success, and in the long term, it results in an economic } \\
\text { stabilization with great benefits }\end{array}$ & $\begin{array}{l}\text { There are no short-term benefits, and it requires large } \\
\text { investments that probably not all countries will be able } \\
\text { to achieve }\end{array}$ \\
\hline
\end{tabular}

Medical Resource Management Under Emergency Scenarios

- The development of a mathematical model that considers social aspects such as economic inequality or vulnerable groups of people and also considering the different types of vaccines on the market, where the benefits are reflected over time either by reducing the mortality rate or by reducing the number of years lost.

- An energy analysis that uses the 15-min cities and replaces the use of chemical disinfectants with energy disinfectants, such as steam disinfection, would surely obtain great benefits and could encourage the governments of different regions to focus urban development to a scheme similar to the one proposed.

- The development of a mathematical model that uses different selection criteria for the correct management of all waste generated in urban areas, but that additionally considers that a certain part of this waste can serve as an alternative energy source using a multi-optimiza- tion approach that minimizes the environmental impact and maximizes the profits generated by this strategy.

- The implementations of new business models based on the circular economy require a high level of investment of time and money. There is still much development in this field, and it is probably the best line of research to follow due to its great economic and environmental benefits.

- Probably for the management of medical resources under emergency scenarios, it is widely discussed from the ethical point of view. However, it is necessary to implement all these ideas in a robust mathematical model that not only allocates medical resources based on the existing deficiencies. These models would be especially useful in regions with a high level of inequality.

As is to be expected, not all the new lines of research will follow the aforementioned routes. Perhaps in the future, 


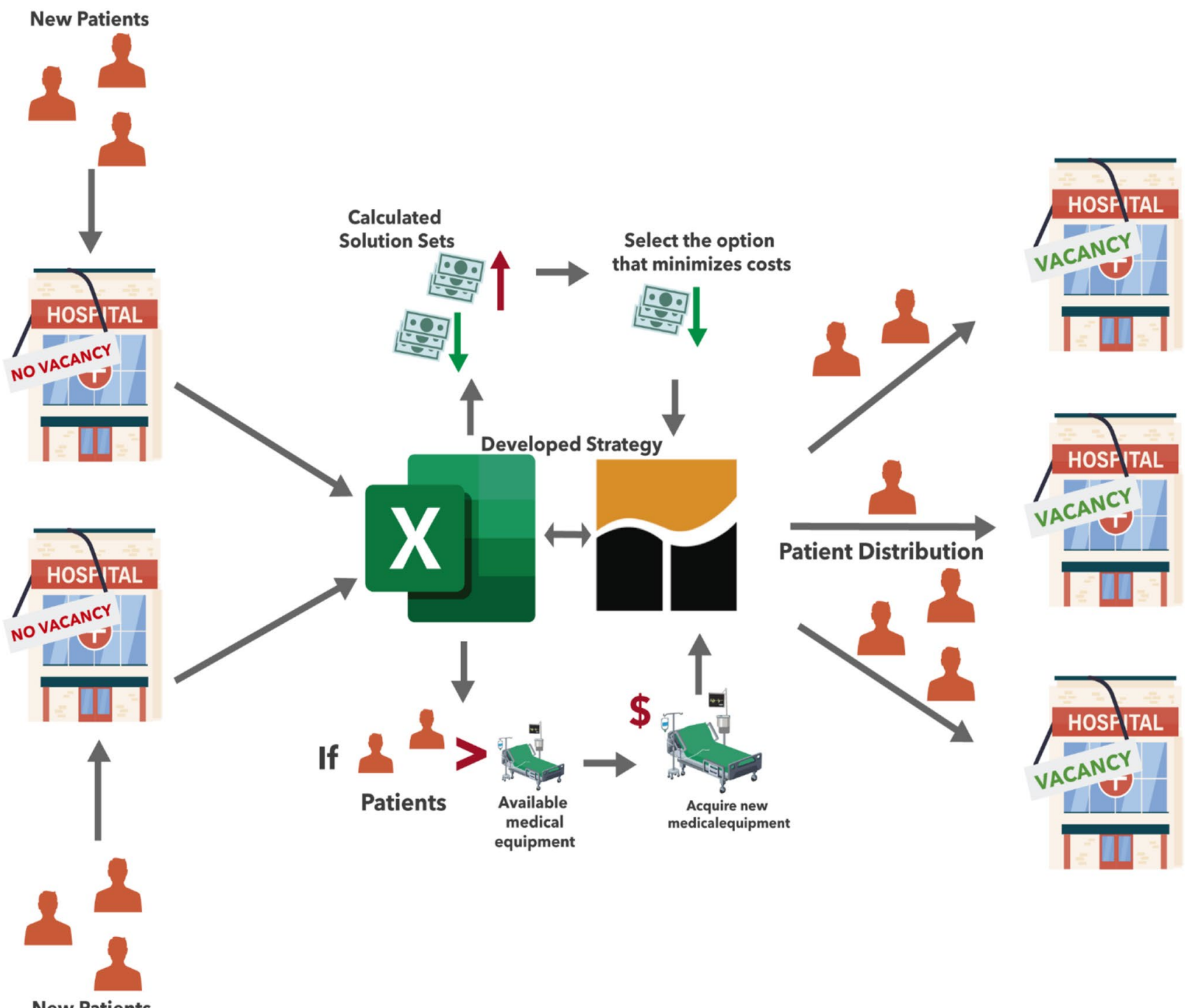

New Patients

Fig. 18 Distribution scheme for patients considering cost minimization

Table 6 Comparison between the proposed strategies for the distribution and allocation of medical resources

\begin{tabular}{|c|c|c|}
\hline Strategies & Advantages & Disadvantages \\
\hline $\begin{array}{l}\text { Hernández-Pérez } \\
\text { and Ponce-Ortega } \\
(2021)\end{array}$ & $\begin{array}{l}\text { General methodology that implements mathematical mod- } \\
\text { els and allows to quantify the benefits obtained taking } \\
\text { into account the uncertainty }\end{array}$ & $\begin{array}{l}\text { It does not consider the possible inequality between the } \\
\text { different patients }\end{array}$ \\
\hline Zhu et al. (2021) & $\begin{array}{l}\text { The proposed model allows an early estimate of the number } \\
\text { of ICUs that might be required, facilitating the manage- } \\
\text { ment of medical resources }\end{array}$ & $\begin{array}{l}\text { The model alone could be insufficient to obtain significant } \\
\text { benefits, so it would have to be used in conjunction with } \\
\text { other strategies }\end{array}$ \\
\hline Emanuel et al. (2020) & $\begin{array}{l}\text { The recommendations given allow establishing restrictions } \\
\text { that could be implemented in future mathematical models } \\
\text { allowing a fair allocation of existing medical resources }\end{array}$ & $\begin{array}{l}\text { Carrying out a mathematical model that considers every- } \\
\text { thing discussed in this work could be an arduous task, } \\
\text { and it may not be possible to collect enough data to use } \\
\text { all the recommendations mentioned }\end{array}$ \\
\hline
\end{tabular}


new ideas will be raised that allow us to obtain even greater benefits, but it is undeniable that the development of the present and new strategies will allow us to be better prepared for future pandemics.

\section{Conclusions}

In this work, some strategies used to reduce the impact generated by the COVID-19 in different areas such as vaccine allocation, energy management, medical resources management, and waste management were discussed. In the reviewed works, it is observed that the strategies presented can be compatible with each other, generating a greater benefit. It would be especially useful to develop quantitative models on those strategies that present qualitative benefits, to be able to compare them and find the best one. However, the applicability of each of the strategies depends on many requirements that are probably not present in underdeveloped countries, such as the proper management of waste generated by the population, to name a few. Undoubtedly, all the strategies presented would generate benefits if they are applied, but a relevant factor to take into account is the short- and long-term benefits. For instance, the implementation of 15-min cities may produce better results than other energy strategies, but it requires a large investment of money and especially time. Therefore, in the case of applying this strategy, the results would be observed in a long time, maybe for the next pandemic. On the other hand, the strategies proposed to stabilize the economy once the epidemic can be considered over also show long-term results. This may turn out to be an uncertain future since there is no way to accurately predict what will happen. Furthermore, global economic models are likely to change, and depending on the strategy that is implemented, we could witness an economic crisis of great relevance. Therefore, it may be necessary to use different strategies depending on the scenarios that arise to achieve economic stabilization in the medium-long term. Finally, vaccine allocation is possibly the most relevant short-term challenge that all governments are currently facing. Here, the strategies used must be meticulously analyzed since the socioeconomic situation worldwide can be highly different. The strategies that classify their population only by age (considering everyone as equal within this classification) could only be applied in certain regions where there are no significant levels of inequality. Thus, models capable of taking into account the level of inequality of individuals should be considered, especially for underdeveloped and developing countries.

Funding The authors received financial support from CONACyT and CIC-UMSNH.
Data Availability The data that support this manuscript are available on request from the corresponding author.

\section{Declarations}

Conflict of Interest The authors declare no competing interests.

\section{References}

Abu-Rayash A, Dincer I (2020) Analysis of the electricity demand trends amidst the COVID-19 coronavirus pandemic. Energy Res Soc Sci 68:101682. https://doi.org/10.1016/j.erss.2020.101682

Aizenman J, Ito H (2020) Post COVID-19 exit strategies and emerging markets economic challenges. National Bureau of Economic Research. Working Paper 27966. https://doi.org/10.3386/ w27966

Chen N, Zhou M, Dong X, Qu J, Gong F, Han Y (2020) Epidemiological L, and clinical characteristics of 99 cases of 2019 novel coronavirus pneumonia in Wuhan, China: a descriptive study. Lancet 395(10223):507-513. https://doi.org/10.1016/S0140-6736(20) 30211-7

Chofreh AG, Goni FA, Klemeš JJ, Seyed Moosavi SM, Davoudi M, Zeinalnezhad M (2021) Covid-19 shock: development of strategic management framework for global energy. Renew Sustain Energy Rev 139:110643. https://doi.org/10.1016/j.rser.2020.110643

Christian MD, Sprung CL, King MA (2014) Triage: care of the critically ill and injured during pandemics and disasters: CHEST consensus statement. Chest 146(4 Suppl):e61S-e74S. https://doi.org/ 10.1378/chest.14-0736

CIDRAP (2021) Pre-COVID surge analysis shows lack of hospital pandemic planning, Center for Infectious Disease Research and Policy. Available at: https://www.cidrap.umn.edu/news-persp ective/2021/03/pre-covid-surge-analysis-shows-lack-hospitalpandemic-planning. Accessed 6 June 2021

Craxì L, Casuccio A, Amodio E, Restivo V (2021) Who should get COVID-19 vaccine first? A survey to evaluate hospital workers' opinion. Vaccines 9(3):189. https://doi.org/10.3390/vaccines90 30189

De Sio S, Cedrone F, Nieto HA, Lapteva E, Perri R, Greco E, Mucci N, Pacella E, Buomprisco G (2021) Telework and its effects on mental health during the COVID-19 lockdown. Eur Rev Med Pharmacol Sci 25(10):3914-3922. https://doi.org/10.26355/eurrev_202105_25961

Dulce-Chamorro E, Martinez-de-Pison FJ (2021) An advanced methodology to enhance energy efficiency in a hospital cooling-water system. J Build Eng 102839. https://doi.org/10.1016/j.jobe.2021. 102839

Dwivedi YK, Hughes DL, Coombs C, Constantiou I, Duan Y, Edwards JS, Upadhyay N (2020) Impact of COVID-19 pandemic on information management research and practice: transforming education, work and life. Int J Inf Manag 55:102211. https://doi.org/10. 1016/j.ijinfomgt.2020.102211

Emanuel EJ, Persad G, Upshur R, Thome B, Parker M, Glickman A, Zhang C, Boyle C, Smith M, Phillips JP (2020) Fair allocation of scarce medical resources in the time of COVID-19. N Engl J Med 382(21):2049-2055. https://doi.org/10.1056/NEJMsb2005114

European Commission (2021) EU vaccines strategy. Available at: https://ec.europa.eu/info/live-work-travel-eu/coronavirus-respo nse/public-health/eu-vaccines-strategy_en. Accessed 6 June 2021

Faigle U, Grabisch M, Jiménez-Losada A, Ordóñez M (2016) Games on concept lattices: Shapley value and core. Discret Appl Math 198:29-47. https://doi.org/10.1016/j.dam.2015.08.004 
Fan YV, Pintarič ZN, Klemeš JJ (2020) Emerging tools for energy system design increasing economic and environmental sustainability. Energies 13(16):4062. https://doi.org/10.3390/en13164062

Ferreras E, Chizema-Kawesha E, Blake A, Chewe O, Mwaba J, Zulu G, Luquero FJ (2018) Single-dose cholera vaccine in response to an outbreak in Zambia. N Engl J Med 378(6):577-579. https:// doi.org/10.1056/nejmc1711583

FIRI (2021) Research report of the disinfection industry in China 2020. Forward Industry Research Institute (FIRI). https://pdf.dfcfw.com/ pdf/H3_AP202003181376603847_1.pdf. Accessed 8 June 2021

Gardiner B (2020) Pollution made COVID-19 worse. Now, lockdowns are clearing the air. National Geographic. https://www.nationalge ographic.com/science/2020/04/pollution-made-the-pandemicworse-but-lockdowns-clean-the-sky/. Accessed 9 Mar 2021

Guan WJ, Ni ZY, Hu Y, Liang WH, Ou CQ, He JX, Zhong NS (2020) Clinical characteristics of coronavirus disease 2019 in China. $\mathrm{N}$ Engl J Med 382(18):1708-1720. https://doi.org/10.1101/2020.02. 06.20020974

Harjule P, Tiwari V, Kumar A (2021) Mathematical models to predict COVID-19 outbreak: an interim review. J Interdiscip Math 1-26. https://doi.org/10.1080/09720502.2020.1848316

HCHP (2020) Health Commission of Hubei Province: epidemic situation of COVID-19 in Hubei province. Available online at: http:// www.hubei.gov.cn/fbjd/dtyw/202003/t20200330_2196392.shtml. Accessed 21 Mar 2021

Hernández-Pérez LG, Ponce-Ortega JM (2021) Multi-objective optimization approach based on deterministic and metaheuristic techniques to resource management in health crisis scenarios under uncertainty. Process Integration and Optimization for Sustainability, Advance online publication. https://doi.org/10.1007/ s41660-020-00154-3

IEA (2019) Cooling report. Available at: https://www.iea.org/reports/ tracking-buildings/cooling. Accessed 16 June 2021

Ilyas S, Srivastava RR, Kim H (2020) Disinfection technology and strategies for COVID-19 hospital and bio-medical waste management. Sci Total Environ 749:141652. https://doi.org/10.1016/j. scitotenv.2020.141652

Inkster B, O’Brien R, Selby E, Joshi S, Subramanian V, Kadaba M, Mateen BA (2020) Digital health management during and beyond the COVID-19 pandemic: opportunities, barriers, and recommendations. JMIR Mental Health 7(7):e19246. https://doi.org/ $10.2196 / 19246$

Jiang P, Fan YV, Klemeš JJ (2021) Impacts of COVID-19 on energy demand and consumption: challenges, lessons and emerging opportunities. Appl Energy 285:116441. https://doi.org/10.1016/j. apenergy.2021.116441

Kanellopoulos DN (2011) How can teleworking be pro-poor? J Enterp Inf Manag 24(1):8-29. https://doi.org/10.1108/174103911110974 01

Klemeš JJ, Fan YV, Jiang P (2020) The energy and environmental footprints of COVID-19 fighting measures - PPE, disinfection, supply chains. Energy 211:118701. https://doi.org/10.1016/j. energy.2020.118701

Konda A, Prakash A, Moss GA, Schmoldt M, Grant GD, Guha S (2020) Aerosol filtration efficiency of common fabrics used in respiratory cloth masks. ACS Nano 14(5):6339-6347. https://doi. org/10.1021/acsnano.0c03252

Krarti M, Aldubyan M (2021) Review analysis of COVID-19 impact on electricity demand for residential buildings. Renew Sustain Energy Rev 143:110888. https://doi.org/10.1016/j.rser.2021. 110888

Krog L, Sperling K (2019) A comprehensive framework for strategic energy planning based on Danish and international insights. Energ Strat Rev 24:83-93. https://doi.org/10.1016/j.esr.2019.02.005

Mallapur C (2020) Sanitation workers at risk from discarded medical waste related to COVID-19. IndiaSpend. https://www.india spend.com/sanitation-workersat-risk-from-discarded-medicalwaste-related-tocovid-19/. Accessed 9 Mar 2021

Matrajt L, Eaton J, Leung T, Brown E (2021) Optimizing vaccine allocation for COVID-19 vaccines shows the potential role of single-dose vaccination. Nat Commun 12:3449. https://doi.org/ 10.1038/s41467-021-23761-1

Matrajt L, Eaton J, Leung T, Brown E (2020) Vaccine optimization for COVID-19, who to vaccinate first? medRxiv: The preprint server for health sciences. https://doi.org/10.1101/2020.08.14. 20175257

Mohamadou Y, Halidou A, Kapen PT (2020) A review of mathematical modeling, artificial intelligence and datasets used in the study, prediction and management of COVID-19. Appl Intell 50(11):3913-3925. https://doi.org/10.1007/s10489-020-01770-9

Morawska JW, Tang W, Bahnfleth PM, Bluyssen A, Boerstra G, Buonann J, Cao S, Dancer A, Floto F, Franchimon C, Haworth J, Hogeling C, Isaxon JL, Jimenez J, Kurnitski Y, Li M, Loomans G, Marks LC, Marr L, Maz-zarella AK, Melikov S, Miller DK, Milton W, Nazaroff PV, Nielsen C, Noakes J, Peccia X, Querol C, Sekhar O, Seppänen S, Ichi Tanabe R, Tellier KW, Tham P, Wargocki A, Wierzbicka M, Yao L (2020) How can airborne transmission of covid-19 indoors be minimized? Environ Int 142:105832. https://doi.org/10.1016/j.envint.2020.105832

Munguía-López AC, Ponce-Ortega JM (2021) Fair allocation of potential COVID-19 vaccines using an optimization-based strategy. Process Integr Optim Sustain 5(1):3-12. https://doi.org/10.1007/ s41660-020-00141-8

Olivas-Martínez A, Cárdenas-Fragoso JL, Jiménez JV, Lozano-Cruz OA, Ortiz-Brizuela E et al (2021) In-hospital mortality from severe COVID-19 in a tertiary care center in Mexico City; causes of death, risk factors and the impact of hospital saturation. PLoS ONE 16(2):e0245772. https://doi.org/10.1371/journal.pone.02457 72

ONS (2021) International comparisons of GDP during the coronavirus (COVID-19) pandemic. Available at: https://www.ons.gov.uk/ economy/grossdomesticproductgdp/articles/internationalcompari sonsofgdpduringthecoronaviruscovid19pandemic/2021-02-01. Accessed 6 June 2021

Patrício-Silva AL, Prata JC, Walker TR, Duarte AC, Ouyang W, Barcelò D, Rocha-Santos T (2021) Increased plastic pollution due to COVID-19 pandemic: Challenges and recommendations. Chem Eng J 405:126683. https://doi.org/10.1016/j.cej.2020.126683

Perniola S, Alivernini S, Varriano V, Paglionico A, Tanti G, Rubortone P (2020) Telemedicine will not keep us apart in COVID-19 pandemic. Ann Rheum Dis 80(4):e48. https://doi.org/10.1136/annrh eumdis-2020-218022

Reimer J (2020) The 15-minute infrastructure trend that could change public transit as we know it. https://360.here.com/15-minute-cities-infrastructure. Accessed 9 Mar 2021

Saadat S, Rawtani D, Hussain CM (2020) Environmental perspective of COVID-19. Sci Total Environ 728:138870. https://doi.org/10. 1016/j.scitotenv.2020.138870

SaniVap (2013) Steam biocleaning: the hygienic solution for healthcare establishments. Available at: www.sanivap.fr/en/health/le-bione ttoyage-vapeur. Accessed 14 June 2021

Schulz AS, Uhan NA (2013) Approximating the least core value and least core of cooperative games with supermodular costs. Discret Optim 10(2):163-180. https://doi.org/10.1016/j.disopt.2013.02. 002

Senthilkumar VS, Reddy KS, Subramaniam U (2020) COVID-19: impact analysis and recommendations for power and energy sector operation. Appl Energy 279:115739. https://doi.org/10.1016/j. apenergy.2020.115739

SGV (2016) 20-minute neighbourhoods. Available at: https://www. planmelbourne.vic.gov.au/current-projects/20-minute-neighbourh oods. Accessed 9 Mar 2021 
Sharma HB, Vanapalli KR, Cheela VS, Ranjan VP, Jaglan AK, Dubey B, ... Bhattacharya J (2020) Challenges, opportunities, and innovations for effective solid waste management during and post COVID - 19 pandemic. Resour Conserv Recycl 162:105052. https://doi.org/10.1016/j.resconrec.2020.105052

Shim E (2021) Optimal allocation of the limited COVID-19 vaccine supply in South Korea. J Clin Med 10(4):591. https://doi.org/10. 3390/jcm10040591

Silveira EA, Kliemann N, Noll M, Sarrafzadegan N, de Oliveira C (2021) Visceral obesity and incident cancer and cardiovascular disease: an integrative review of the epidemiological evidence. Obes Rev 22(1):e13088. https://doi.org/10.1111/obr.13088

Sisson P (2020) How the '15-Minute City' Could Help Post-Pandemic Recovery. Available at: https://www.bloomberg.com/news/artic les/2020-07-15/mayors-tout-the-15-minute-city-as-covid-recov ery. Accessed 9 Mar 2021

Song L, Zhou Y (2020) The COVID-19 pandemic and its impact on the global economy: what does it take to turn crisis into opportunity? Chin World Econ 28(4):1-25. https://doi.org/10.1111/cwe.12349

The Local (2021) COMPARE: the different strategies used in Europe to vaccinate against Covid-19. Available at: https://www.thelocal. de/20210415/compared-how-countries-around-europe-are-organ ising-their-covid-vaccine-rollouts/. Accessed 6 June 2021

Tijs S (2003) Introduction to game theory. Texts and readings in mathematics. Springer, Gurgaon, India

Torres-Ramírez C, Orozco-Rivera E (2020) Covid-19. Vacunas y vacunación notas estratégicas, 118 Available at: http://bibliodigitalibd. senado.gob.mx/handle/123456789/5079. Accessed 9 Mar 2021

UNEP (2020) Waste management during the COVID-19 pandemic. Available at: https://wedocs.unep.org/bitstream/handle/20.500. 11822/33416/WMC-19.pdf?sequence=1\&isAllowed=y. Accessed 9 Mar 2021

Valizadeh J, Mozafari P (2021) A novel cooperative model in the collection of infectious waste in COVID-19 pandemic. J Model Manag, Advance online publication. https://doi.org/10.1108/ JM2-07-2020-0189

Vesga J, Granados Acuña G, Sierra Carrillo J (2015) The value of Shapley as a strategy for Resource Optimization on Power Line Communication (PLC). Ingeniería y Ciencia 11(22):189-211. https://doi.org/10.17230/ingciencia.11.22.9

Wang J, Shen J, Ye D, Yan X, Zhang Y, Yang W, Li X, Wang J, Zhang L, Pan L (2020a) Disinfection technology of hospital wastes and wastewater: suggestions for disinfection strategy during coronavirus disease 2019 (COVID-19) pandemic in China. Environ Pollut 262:114665. https://doi.org/10.1016/j.envpol.2020.114665
Wang N, Fu Y, Zhang H, Shi H (2020b) An evaluation of mathematical models for the outbreak of COVID-19. Precis Clin Med 3(2):8593. https://doi.org/10.1093/pcmedi/pbaa016

Wu Z, McGoogan JM (2020) Characteristics of and important lessons from the coronavirus disease 2019 (COVID-19) Outbreak in China: Summary of a Report of 72314 cases from the Chinese center for disease control and prevention. JAMA 323(13):12391242. https://doi.org/10.1001/jama.2020.2648

Wu C, Chen X, Cai Y, Xia J, Zhou X, Xu S (2020) Risk factors associated with acute respiratory distress syndrome and death in patients with coronavirus disease 2019 pneumonia in Wuhan, China. JAMA Intern Med 180:934-943. https://doi.org/10.1001/jamai nternmed.2020.0994

Wuyts W, Marin J, Brusselaers J, Vrancken K (2020) Circular economy as a COVID-19 cure? Resour Conserv Recycl 162:105016. https:// doi.org/10.1016/j.resconrec.2020.105016

Xinhua net. (2020) Nearly 2,000 t of disinfectants were used to promote enhanced disinfection of urban drainage and sewage facilities in Wuhan. 2020. www.xinhuanet.com/fortune/2020-02/20/c_11256 00148.htm. Accessed 9 Mar 2021

Zhang X, Pellegrino F, Shen J, Copertaro B, Huang P, Saini PK, Lovati M (2020) A preliminary simulation study about the impact of COVID-19 crisis on energy demand of a building mix at a district in Sweden. Appl Energy 280:115954. https://doi.org/10.1016/j. apenergy.2020.115954

Zhao N, You F (2021) Food-energy-water-waste nexus systems optimization for New York State under the COVID-19 pandemic to alleviate health and environmental concerns. Appl Energy 282:116181. https://doi.org/10.1016/j.apenergy.2020.116181

Zhu W, Zhang H, Li Y, Ding Z, Liu Z, Ruan Y, Feng H, Li G, Liu B, He F, Zhou N, Jiang J, Wen Z, Xu G, Zhao J, Zhang B, Wang D, Tang Z, Wang H, Liu J (2021) Optimizing management to reduce the mortality of COVID-19: experience from a designated hospital for severely and critically ill patients in China. Front Med 8:582764. https://doi.org/10.3389/fmed.2021.582764

Publisher's Note Springer Nature remains neutral with regard to jurisdictional claims in published maps and institutional affiliations. 